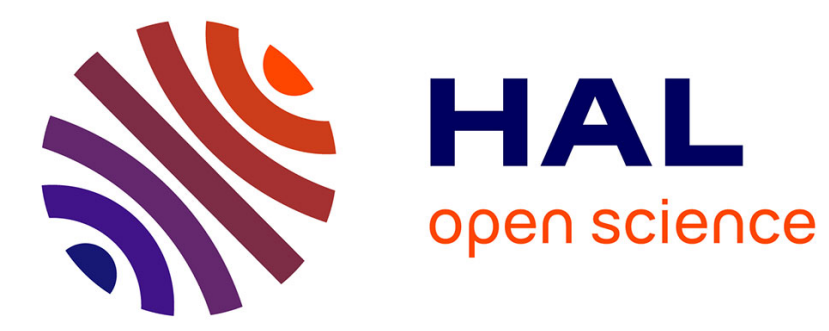

\title{
La communauté chiite, première victime de l'implosion de la société irakienne \\ Pierre-Jean Luizard
}

\section{To cite this version:}

Pierre-Jean Luizard. La communauté chiite, première victime de l'implosion de la société irakienne.

Hérodote - Revue de géographie et de géopolitique, 2007, pp. 118-154. halshs-00277639

\section{HAL Id: halshs-00277639 \\ https://shs.hal.science/halshs-00277639}

Submitted on 7 May 2008

HAL is a multi-disciplinary open access archive for the deposit and dissemination of scientific research documents, whether they are published or not. The documents may come from teaching and research institutions in France or abroad, or from public or private research centers.
L'archive ouverte pluridisciplinaire HAL, est destinée au dépôt et à la diffusion de documents scientifiques de niveau recherche, publiés ou non, émanant des établissements d'enseignement et de recherche français ou étrangers, des laboratoires publics ou privés. 
La communauté chiite en Irak sous le coup de l'implosion générale de la société

\author{
Pierre-Jean Luizard \\ (Groupe Sociétés, \\ Religions, Laïcités - \\ CNRS/EPHE)
}

L'avenir de la communauté chiite d'Irak détermine en grande partie celui du chiisme dans le monde. L'Irak est le berceau du chiisme. C'est là, en effet, qu'eurent lieu les événements fondateurs de la seconde branche de l'islam : c'est à Koufa, près de Nadjaf, qu'Ali, cousin et gendre du Prophète, transporta le siège du califat en 656, et c'est là qu'il fut assassiné en 661, alors qu'il faisait valoir son droit au califat face au clan des Omeyyades. C'est à Kerbéla, en 680, que son fils Hussein mourut en héros, dans des circonstances que les chiites continuent à commémorer rituellement lors d'impressionnantes cérémonies de deuil (Achoura et Arba'îniyya). A partir de ce moment, les chiites ont considéré les califes comme des usurpateurs, le seul pouvoir légitime, à leurs yeux, étant la lignée de douze Imams descendants du Prophète et réputés infaillibles.

\title{
Le berceau du chiisme
}

Selon la tradition chiite, le XIIe Imam disparut en 874 dans les souterrains de la ville de Samarra. Pour les croyants, il n'était pas mort, mais simplement " occulté », et continuait à diriger sa communauté par l'intermédiaire de quatre "agents" qui se succédèrent jusqu'en 941, date à laquelle a commencé la période dite d' "Occultation majeure ». Ce douzième Imam était promis à un retour triomphal sur terre et réapparaîtrait en tant que Mahdi au moment choisi par Dieu. L'attente messianique du retour de l'Imam caché dure toujours. Au fil des siècles, les oulémas chiites ont peu à peu récupéré l'essentiel des prérogatives de l'Imam caché (à l'exception de l'infaillibilité) jusqu'à se présenter, à la fin du XVIIIe siècle, comme ses représentants sur terre.

Le dogme chiite fut élaboré d'abord à Baghdad, puis à Hilla, au sud de Baghdad, à Koufa, et, enfin, dans les quatre villes saintes édifiées autour des tombeaux des Imams : Nadjaf, Kerbéla, Kazimayn (ou Kazimiyya) et Samarra se transformèrent en lieux de pèlerinages vénérés, où les centres d'études religieuses florissaient. A partir du XIXe siècle, les villes saintes chiites devinrent le siège d'une autorité qui disputa de plus en plus ouvertement sa suprématie au pouvoir politique. Les oulémas se posent alors comme une 
direction à la fois spirituelle et temporelle. Nadjaf a été le berceau de ce chiisme moderne qui devait aboutir bien plus tard à la révolution islamique menée par Khomeyni en Iran, au Hezbollah au Liban et à la revendication du pouvoir par les oulémas.

\section{Les chiites d'hier et d'aujourd'hui}

La société irakienne est composée, rappelons-le, de trois grandes communautés. Les chiites, Arabes dans leur immense majorité, forment environ $54 \%$ de la population. Les Arabes sunnites et les Kurdes, ces derniers étant également sunnites, sont pratiquement à parité, puisqu'ils représentent chacun entre 22 et $24 \%$ de la population, avec une légère prédominance des Arabes sunnites. Plus de treize millions de chiites vivent sur les rives du Tigre et de l'Euphrate : ils représentent la plus importante communauté chiite du monde arabe, très loin devant le Liban. Une majorité des chiites irakiens sont des convertis à une date récente. Le mouvement de conversion se poursuivit jusqu'au début du XXe siècle. Il exprimait l'adéquation des sentiments de tribus anciennement sunnites confrontées à la déchéance au regard des valeurs bédouines liée à leur sédentarisation. Au début du XXe siècle, un pays chiite quasi homogène s'était constitué, depuis le sud de Baghdad jusqu'au Golfe.

Par leur poids démographique comme par leur enracinement historique, les chiites d'Irak sont aussi la minorité la plus importante à l'échelle du monde arabe, largement sunnite. La communauté, essentiellement arabe, compte cependant également des Persans, des Kurdes et des Turkmènes (environ 40\% des Turkmènes d'Irak). Les Kurdes chiites (appelés Kurdes Faylis) ont payé au prix fort le fait d'être à la fois kurdes et chiites : le régime baassiste les a en effet déportés en masse vers l'Iran dans les années 1970 et 1980.

L'histoire des chiites d'Irak n'est pas séparée de celle des sunnites, mais elle est distincte. Cette histoire a été occultée par les régimes successifs de l'ancien système fondé par les Britanniques en 1920, qui donnait l'exclusivité du pouvoir à des élites issues de la minorité arabe sunnite du pays. Etre chiite, c'est d'abord une culture particulière, une culture marquée par des siècles d'exclusion du gouvernement, ainsi que par la prédominance du clergé. Le milieu clérical a façonné des générations entières. Son hostilité aux pouvoirs en place, son aptitude à lutter contre la domination étrangère et contre le despotisme, ont orienté les esprits vers la contestation de l'ordre gouvernemental, en encourageant un désir de justice sociale et un patriotisme irakien qu'il ne faut pas confondre avec le nationalisme arabe. Le milieu clérical chiite a été le terreau ont sont apparus les pionniers de la presse en arabe à l'époque ottomane. Il a été l'animateur des premiers débats politiques du pays. Il a aussi développé les arts et les lettres, sans parler de l'architecture ou des travaux d'irrigation des campagnes environnant les villes saintes. Son cosmopolitisme, son ouverture vers l'extérieur, sur les cultures du chiisme, arabe, persane, indienne, africaine, mais aussi sur les idées européennes, expliquent qu'une grande partie des 
intellectuels et des hommes de lettres du pays soient chiites. La société chiite a connu un anticléricalisme que bien des sunnites, chez qui les oulémas ont toujours été de simples fonctionnaires du gouvernement, ont du mal à saisir. C'est ainsi que, dans les années 1930-1950, un grand nombre de chiites se rallièrent aux idées communistes, et dans une mesure bien moindre, baassistes. Après le reflux de la vague communiste, les tendances laïques sont redevenues minoritaires, mais des chiites continuent à adhérer au communisme, ou appartiennent à des courants se réclamant du libéralisme.

\section{Une culture chiite multiforme}

La culture chiite se caractérise également par un rapport particulier à l'argent et au commerce : exclus du gouvernement et de l'armée, les chiites se sont rattrapés dans le seul domaine d'activité qui ne leur était pas fermé, le commerce. Favorisés par les liens entre les grands religieux et les réseaux commerciaux tissés depuis le Liban jusqu'en Inde en passant par l'Iran, d'importantes fortunes chiites s'étaient constituées au fil des siècles, avec la bénédiction des oulémas. La communauté chiite a ainsi donné naissance à une véritable bourgeoisie, dont la famille Chalabi, à laquelle appartient l'exprésident du Congrès national irakien (CNI), qui regroupait à Londres les opposants au régime de Saddam Hussein, est un exemple. Quant aux Kubba, famille à laquelle appartient Layth Kubba, ex-porte-parole du CNI à Londres, et aujourd'hui conseiller du président irakien pour la sécurité, ils avaient fait fortune à la fin du XIXe siècle grâce au commerce de la soie. Avant la guerre entre l'Irak et l'Iran (1980-1988), les Irakiens les plus riches étaient des chiites, mais les plus pauvres l'étaient également. La communauté chiite est ainsi la seule communauté d'Irak à avoir une véritable structure de classes capitaliste, puisqu'on y rencontre, outre le clergé, une classe ouvrière nombreuse, une paysannerie, une riche et influente bourgeoisie commerçante et une classe moyenne, du moins jusqu'à l'embargo (1991). Du fait de cette segmentation, qui transcende les solidarités locales et tribales, la communauté chiite avait une aptitude à constituer une société civile que n'ont pas les autres communautés, en particulier les Arabes sunnites et les Kurdes. Il n'existe pas en effet de bourgeoisie nationale en Irak, à l'image du Bazar d'Iran, mais des classes commerçantes communautaires, où les juifs et les chiites ont occupé des places prédominantes. Les chiites remplacèrent les juifs, qui émigrèrent dans les années 1940, s'imposant encore davantage dans le domaine du commerce et de l'entreprise. Ces activités expliquent que les idées libérales se soient diffusées dans la communauté qui est également la plus ouverte aux idées constitutionnelles.

\section{Le premier Mandat}

En 1920, le système politique fondé par les Britanniques instaurait une discrimination confessionnelle et ethnique inavouée. Sous des aspects modernes 
et malgré la proclamation de son identité arabe, le nouvel Etat excluait les trois quarts de la population irakienne : les chiites et, à partir de 1925 (année du rattachement du vilayet de Mossoul à l'Irak), les Kurdes. Le pouvoir était conçu pour être le monopole d'élites issues de la minorité arabo-sunnite. Les chiites s'étaient opposés les armes à la main à l'invasion britannique, lors du djihad de 1914-18, puis au mandat britannique, lors de la Révolution de 1920, et à son corollaire, l'accaparement du pouvoir par une minorité confessionnelle et ethnique. Vaincus militairement, le mouvement religieux chiite entama une traversée du désert de près d'un demi-siècle, avant de renaître à partir de la fin des années 1950.

Les Britanniques encouragèrent à partir des années 1920 l'émergence d'une classe de grands cheikhs tribaux dans lesquels ils cherchaient un contrepoids à l'autorité du roi Faysal, qu'ils avaient pourtant eux-mêmes mis en place. Ils trouvèrent dans les cheikhs tribaux, dont une bonne partie était chiite, un puissant levier leur permettant de diviser la société tribale, et plus particulièrement le pays chiite. Ces cheikhs tribaux, promus propriétaires d'immenses domaines fonciers, en arrivèrent à considérer les paysans qui cultivaient leurs terres comme leur propriété. L'Irak a sans doute été l'exemple le plus abouti de la constitution au XXe siècle d'un féodalisme au sens européen du terme. Ce nouvel asservissement, qui avait débuté à la fin de l'époque ottomane, poussa les paysans sans terres à fuir. Pour échapper à l'esclavage, ils migrèrent en masse vers les grandes villes, dépeuplant les campagnes. Les campagnes tribales, qui avaient été la base politique des mujtahids ${ }^{l}$ des villes saintes, se vidèrent littéralement à partir des années 1930. L'exode rural se poursuivit après la Seconde Guerre mondiale. Des quartiers de bidonvilles les accueillirent à Baghdad et à Bassora. C'est ainsi que se forma l'immense quartier connu aujourd'hui sous le nom de Sadr City. Ce quartier accueillit des centaines de milliers de paysans originaires des provinces orientales du Tigre (Kout et Amara), d'où leur nom de Shâragwa (les "Orientaux » en dialecte irakien).

\section{Un système de domination confessionnel inavoué}

La nature confessionnelle et ethnique du système survécut aux révolutions et aux coups d'Etat. Le régime de Saddam Hussein en fut le dernier avatar. Dans un premier temps, face au danger de la révolution islamique en Iran, les grandes puissances apportèrent au régime de Saddam un soutien qui lui permit de survivre, à un moment où toutes les oppositions conjuguées auraient normalement dû aboutir à sa chute (fin des années 1970). Les chiites payèrent un prix effarant à cette alliance. Extension au-delà des frontières d'une guerre civile larvée qui opposait dans les années 1970 le pouvoir bassiste au mouvement religieux chiite renaissant, les huit ans de guerre entre l'Iran et l'Irak furent un

\footnotetext{
${ }^{1}$ Les mujtahids sont les religieux habilités par leur science à pratiquer l'ijtihâd, l'effort raisonné d'interprétation des textes sacrés.
} 
enfer : contraints de rejoindre le front sous peine de condamner leur famille, les soldats chiites furent largement des "malgré nous ». Des centaines de milliers s'enfuirent en Iran et firent la guerre du côté iranien. La guerre fit un million de morts. Après la défaite irakienne de 1991, à la suite de l'invasion du Koweit, les chiites et les Kurdes se soulevèrent, pensant en bonne logique que le régime vivait ses derniers jours. Mais les Alliés décidèrent alors de sauver le régime irakien en lui permettant, une fois encore, de réprimer dans le sang sa population. Les soldats de la Coalition assistèrent l'arme au pied à l'écrasement de l'intifâda chiite de février-mars 1991. La répression fit entre 100000 et 300000 morts.

\section{Le 11 Septembre et ses conséquences}

Le 11 septembre changea la donne. Celui qui avait été l'allié stratégique des Etats-Unis dans les années 1980 et dont les grandes puissances avaient sauvé le régime à deux reprises (1979 et 1991) fut désormais considéré comme la nouvelle cible de ses anciens amis. On en connaît les conséquences, avec la guerre de 2003, la chute du régime irakien et l'occupation de l'Irak par les forces de la Coalition menée par les Etats-Unis.

En 2003, les Etats-Unis se sont adressés aux laissés-pour-compte du système fondé en 1920 par les Britanniques. Les chiites et les Kurdes ont été sollicités pour être les principaux protagonistes d'une reconstruction politique qui a débuté le 13 juillet 2003 avec la proclamation du conseil de gouvernement intérimaire par le proconsul américain à Baghdad. Il s'agissait là d'un renversement d'alliances, vieilles pour certaines de près d'un siècle. Les chiites, en particulier, avaient toujours été à la pointe de la lutte contre la domination occidentale dans la région. La révolution islamique en Iran et le Hezbollah au Liban constituèrent, dans la période récente, les manifestations les plus éclatantes de cet engagement anti-impérialiste. Ce sont pourtant les partis islamistes chiites frères du Hezbollah et proches de l'Iran qui furent accueillis comme partenaires à part entière par Paul Bremer, aux côtés des Kurdes, des communistes et de représentants d'autres communautés ethniques et religieuses. Après un moment d'hésitation, qui dura quelques semaines en avril-mai 2003, les Américains firent donc le choix de l'ex-opposition au régime de Saddam Hussein. Dépourvus de véritables leaders et marginalisés, les Arabes sunnites développèrent un sentiment d'exclusion, porte d'entrée privilégiée pour la mouvance fondamentaliste sunnite internationale proche d'Al-Qaïda.

Mais les chiites ne pouvaient être un allié aussi docile que ne l'avaient été les élites arabo-sunnites envers la Grande-Bretagne. Forts de leur poids démographique (plus de la moitié de la population), de leurs traditions politiques anciennes et solidement ancrées, dotés d'une direction religieuse et politique indépendante des Etats (la marja'iyya, une sorte de Vatican collégiale), ils continuent à se considérer comme le fer de lance de l'identité irakienne et les gardiens de son indépendance. Dès le début, les dirigeants chiites n'ont cessé de 
réaffirmer la nécessité d'un retour à la souveraineté et à l'indépendance du pays. Or, les Américains ont besoin des chiites. Les Kurdes ne peuvent, à eux seuls, jouer le rôle de l'Alliance du Nord en Afghanistan. C'est donc à un jeu de poker menteur que se livrent Américains et chiites, chacun étant persuadé qu'il pourra in fine imposer son choix à l'autre. Au discours américain justifiant l'intégration d'islamistes chiites dans un jeu démocratique au nom de la démocratie répond celui de ces mêmes islamistes pour qui la démocratie n'est qu'un pis aller, une étape vers l'islam.

\section{Renversement d'alliances voué à l'échec}

Ce renversement d'alliances entre une puissance occidentale occupante et les différents acteurs irakiens cache une autre difficulté. Car la reconstruction d'un Etat à partir d'une conception «à la libanaise ", où chacun est promu non pas en fonction de ses opinions politiques et de ses compétences, mais de son appartenance communautaire, a rapidement débouché sur une impasse. La surenchère communautaire qu'implique une telle reconstruction interdit à la puissance occupante de satisfaire tout le monde : donner aux Kurdes mécontente les Arabes; donner aux chiites mécontente les sunnites ; donner aux Turkmènes mécontente les Kurdes, etc. La reconstruction de l'Irak " à la libanaise " s'est vite avérée impossible. Toutefois, les acteurs politiques et religieux chiites se sont tous engagés, avec retard pour certains, dans ce qui semble bien un piège. Un processus à marche forcée qui fait peu de cas des réalités s'est mis en place contre vents et marrées : rédaction de la constitution irakienne provisoire par des juristes américains (février 2004), élections législatives boycottées par les sunnites (30 janvier 2005), référendum sur la Constitution (15 octobre 2005), où le fédéralisme a été adopté, secondes élections législatives (15 décembre 2005). Le 29 août 2004, un attentat avait fait 83 morts à Nadjaf, dont l'ayatollah Muhammad Bâqer al-Hakim. C'était le début d'une guerre confessionnelle qui devait aller crescendo. Le 23 novembre 2006, un attentat a ainsi fait plus de 200 morts à Sadr City, le plus grand quartier chiite de la capitale. La spirale de la violence intercommunautaire semble alors bien échapper à tous les acteurs.

\section{$\underline{\text { A - Une scène politique et religieuse chiite morcelée : }}$}

\section{1) La marja'iyya:}

Au lendemain de la chute du régime de Saddam Hussein, la scène politique chiite était, sans surprise, marquée par la présence d'un clergé qui semblait retrouver ainsi le rôle historique qu'il avait joué dans les années 1910 et 1920. Trois personnalités en particulier paraissaient jouir, pour les uns d'un charisme, pour les autres d'un soutien populaire, susceptibles de leur conférer un rôle politique de premier plan : l'ayatollah Ali Sistani à Nadjaf, vite reconnu 
comme le premier marja,2 des chiites, Muhammad Bâqer al-Hakim, le chef de l'Assemblée suprême de la révolution islamique en Irak (ASRII), après un retour triomphal d'Iran où son exil avait duré près de trente années, et Muqtada alSadr, un jeune imam chiite, dernier rescapé d'un massacre qui avait vu, en 1999, le meurtre sous ses yeux de son père et de ses frères par des sbires du régime de Saddam Hussein. Muhammad Bâqer al-Hakim n'eut pas le temps de capitaliser sa popularité apparente. Il figurait parmi les victimes du terrible attentat de Nadjaf du 29 août 2003, quelques semaines après son retour. Le rôle joué par l'ayatollah Sistani manifestait le retour au grand jour de la marja'iyya, l'institution chiite représentant l'autorité religieuse.

\section{Qui est Ali Sistani?}

Le Grand Ayatollah Ali Sistani est né à Mashhad, en Iran, au sein d'une famille d'oulémas originaire d'Ispahan. Son aïeul, dont il porte le nom, était un ouléma célèbre qui avait fait ses études à Nadjaf. Sous les Séfévides, il avait été nommé Shaikhul-Islâm ${ }^{3}$ par le roi Hussein pour la province du Sistan. Depuis cette époque, la famille est connue sous le nom de Sistani. Sistani commença son éducation religieuse à Mashhad, avant de s'installer dans l'autre ville sainte chiite d'Iran, Qom, en 1949. Après y avoir passé plusieurs années, il partit pour l'Irak en 1951, pour étudier à Nadjaf sous la direction du Grand Ayatollah Abû'l-Qâsem Khû'î. Quand Khû'î mourut en 1992, sa succession rencontra des difficultés dues à la répression en Irak et à la volonté de Téhéran de ne pas être dépossédé de la marja'iyya. Les héritiers de Khû'î désignèrent Sistani comme son successeur. A la mort de l'ayatollah Muhammad Muhammad Sâdeq al-Sadr, le père de Muqtada, en 1999, Sistani fut unanimement reconnu comme le premier marja' d'Irak En tant que tel, il reçoit des dons de millions of dollars, qu'il utilise pour développer ses séminaires et financer des services sociaux. Ayant survécu aux persécutions du régime de Saddam, qui firent de nombreuses victimes parmi les oulémas chiites, son école fut cependant fermée en 1994. Depuis cette époque, il vivait en résidence surveillée à Nadjaf. Son école ne rouvrit qu'en 2003 après que les Américains aient mis à bas le régime de Saddam. Malgré sa réclusion, Sistani avait pu développer un réseau de jeunes oulémas qui le représentent aujourd'hui au sein de la population chiite où il jouit d'une influence décisive.

Sistani est l'héritier d'une marja'iyya quiétiste, à l'image de celle de l'ayatollah Khû'î (1899-1992). Cette tendance est hostile à l'implication des religieux dans le monde politique, qu'elle assimile à celui de la corruption. Une conception à l'opposé de celle de Khomeyni en Iran ou de Muhammad Bâqer alSadr (un cousin et le beau-père de Muqtada, exécuté par le régime de Saddam

\footnotetext{
${ }^{2}$ Désigne chez les chiites un mujtahid pris comme source ou référence et dont l'imitation par les croyants a été rendue obligatoire à partir de la fin du XVIIIe siècle. La marja 'iyya est, selon les époques, incarnée par un marja' suprême, ou composée de plusieurs marja's.

${ }^{3}$ Fonctionnaire supérieur du culte dans une ville ou au niveau de l'Etat.
} 
Hussein en 1980) en Irak. Ce courant quiétiste a toujours fait passer la préservation de l'institution religieuse et de l'enseignement avant les joutes politiques. Sistani était resté silencieux tant que Saddam était au pouvoir. Cependant, maintenir l'indépendance de la marja'iyya sous un régime tel que celui de Saddam était déjà héroïque. Sistani faillit mourir à plusieurs reprises et certains de ses gardes du corps payèrent de leur vie son attachement au maintien de l'indépendance de l'institution religieuse. Toujours est-il que les religieux de cette tendance quiétiste ne sont pas réputés pour être des combattants. Pourtant, c'est le même marja' qui est devenu une personnalité politique incontournable, apparaissant notamment sur les affiches électorales en 2005 en faveur de la nouvelle Constitution, avant d'appeler les chiites, et notamment les femmes, à aller voter lors des élections législatives de décembre 2005. A Nadjaf, trois autres marja's partagent les conceptions de Sistani : Bashir al-Nadjafi (un Pakistanais), cheikh Ishâq al-Fayyâd (un Afghan) et Sayyid Muhammad Sa'id al-Hakim (un oncle du défunt Muhammad Bâqer al-Hakim).

\section{Les autres marja's}

Toujours à Nadjaf, un autre marja', Muhammad al-Ya'qûbi, se réclame de l'héritage de l'ayatollah Muhammad Muhammad Sâdeq al-Sadr, le père de Muqtada. Muhammad al-Ya'qûbi jouit d'une autorité que lui confèrent des preuves manifestes de son adoubement par l' " ayatollah martyr ». Il conteste, à ce titre, l'autorité de Muqtada sur la mouvance sadriste. Cumulant à la fois l'autorité religieuse et une arabité qu'il oppose souvent à la prééminence persane au sein du clergé chiite, il s'est engagé dans le patronage d'un nouveau parti, le parti de la Vertu (Hizb al-Fadîla), qui a longtemps fait cause commune avec les Sadristes de Muqtada, avant de s'en démarquer à partir de 2005.

A Kerbéla, Mahmûd Sarkhi al-Hasani s'est auto-proclamé ayatollah en 2005. A l'instar de Muhammad al-Ya'qûbi, il est réputé pour être autant violemment anti-américain qu'anti-iranien.

\section{D'un Sadr à l'autre}

Enfin, il y a Muqtada al-Sadr. Il est le survivant d'un massacre de sa famille, ordonné par le régime de Saddam Hussein en février 1999, au cours duquel son père, l'ayatollah Muhammad Muhammad Sâdeq al-Sadr (né en 1943) et deux de ses frères furent tués. Son âge est sujet à caution : selon sa biographie, il serait né en 1974, mais, plus vraisemblablement, il doit avoir entre 25 et 30 ans. Son père n'était pas un grand marja' et avait peu en commun avec le "Premier Sadr », l'ayatollah Muhammad Bâqer al-Sadr, exécuté en 1980 par le régime de Saddam Hussein, au début de la guerre entre l'Iran et l'Irak. Autant le « Premier Sadr ", son cousin et beau-père, était un intellectuel et un auteur prolifique, avec l'ambition de donner une réponse islamique aux questions du temps (il fut l'inspirateur direct de la constitution de la République islamique d'Iran), autant 
le «Second Sadr » est resté marqué par les décennies de dictature baassiste et de siège de la marja'iyya par un pouvoir impitoyable. Sa production est très limitée : à la fin des années 1960, il a publié deux livres, Al-islâm wa al-mîthâq al-'âlamiyya li-huqûq al-insân (L'islam et le pacte international des droits de l'homme) et Ma wara al-fiqh (Ce qu'il y a derrière le fiqh), qui sont présents partout aujourd'hui sur les trottoirs de Baghdad (souvent sans référence de leur première édition). C'est peu, comparé à l'œuvre immense du «Premier Sadr ». C'est sa rencontre avec le régime de Saddam Hussein qui l'a sorti de l'anonymat. Nous sommes en 1992, le Grand Ayatollah Abû'l Qâsem Khû'î décède et sa succession s'annonce difficile. La marja'iyya de Nadjaf est, en effet, prise en tenaille entre la répression implacable du régime de Baghdad et une république islamique d'Iran qui a bouleversé le paysage du chiisme et les bases de l'autorité religieuse. Après l'intifâda des chiites de février-mars 1991, Saddam Hussein tente de retrouver des relais au sein de la société chiite en "retribalisant" les réseaux de pouvoir. Les cheikhs de certaines tribus sont promus pour faire régner l'ordre du gouvernement dans leur région, tandis que les autorités irakiennes légitiment des pratiques tribales, notamment aux dépens des femmes... En encourageant les identités tribales, le régime irakien pense trouver un levier au sein d'une société qu'il a durement matée et contourner Nadjaf. Historiquement, en effet, les relations entre les tribus chiites et l'establishment religieux chiite sont faites à la fois de révérence et d'incompréhension. Le monde tribal, imprégné de valeurs arabes bédouines, demeure éloigné de celui, élitiste, savant et cosmopolite de la hawza ${ }^{4}$. Les coutumes tribales ne s'accordent pas toujours avec la sharî'a telle que les mujtahids la conçoivent. Toutefois, il manque une bénédiction autorisée à cette nouvelle politique tribale. Le régime la trouvera en la personne de Muhammad Muhammad Sâdeq al-Sadr : Arabe, il est opposé aux « ayatollahs persans », et il va apporter une caution islamique à un certain nombres de règles tribales. Il consigne le tout dans Fiqh al-'ashâ'ir (Le fiqh des tribus), largement diffusé aujourd'hui à Sadr City et dans les villes du sud irakien. Dans cet ouvrage controversé, Muhammad Muhammad Sâdeq al-Sadr tente de réconcilier la sharî' $a$ avec les coutumes tribales et il donne, notamment, aux chefs tribaux le droit d'appliquer la Loi islamique.

Pendant un temps, Muhammad Muhammad Sâdeq al-Sadr fait figure d' " ayatollah officiel » du régime de Saddam Hussein, et il est dénoncé, à ce titre, par l'ensemble des autorités religieuses chiites. Après la mort à intervalle rapproché de Sebzevârî et de Gulpâyegânî, le successeur reconnu de Khû'î semble être l'ayatollah Sistani, sur la personne duquel s'accordent les héritiers de Khû'î et les dirigeants iraniens. C'est donc contre Sistani que la marja 'iyya de Muhammad Muhammad Sâdeq al-Sadr est mise en avant par Baghdad.

\footnotetext{
${ }^{4}$ La hawza désigne chez les chiites l'ensemble des centres d'enseignement de la religion.
} 
Les baassistes avaient transformé leur patronage tribal en centres de pouvoir. Mais à partir de 1997, Muhammad Muhammad Sâdeq al-Sadr commença à revendiquer le droit de conduire en son nom la prière du vendredi. On sait qu'à la différence de l'Iran, où le pouvoir est considéré comme " chiite ", et où des emâm-e-djom'a (imams du vendredi) étaient traditionnellement nommés par le gouvernement pour le sermon du vendredi dans les grandes mosquées, l'Irak était dépourvu de tels sermons. Les marja's signifiaient là leur non-reconnaissance d'un pouvoir «étranger » et/ou sunnite (le sermon doit citer le nom du souverain ou du président, une condition inacceptable aux yeux des grands ayatollahs). Le sermon du vendredi avait été réhabilité par l'ayatollah Mahdi al-Khâlisi dans les années 1920, comme une manifestation de mobilisation anti-britannique, et il était, à juste titre, considéré par les pouvoirs irakiens en place comme un défi direct, puisqu'il était dit au nom du marja' et qu'était passé sous silence celui du roi ou du président. Toujours en 1997, Muhammad Muhammad Sâdeq al-Sadr commença à s'opposer ouvertement au gouvernement baassiste par une fatwa où il demandait la libération de cent six religieux chiites emprisonnés lors de l'intfâda de 1991.

\section{Muqtada, un défi pour la marja'iyya}

Après la mort de son père, Muqtada, un adolescent qui avait assisté au massacre de sa famille, passa dans la clandestinité. Muhammad Muhammad Sâdeq al-Sadr avait laissé des instructions à ses partisans : à sa mort, il appelait ses imitateurs à se reporter vers l'ayatollah Kâzim al-Husayni al-Hâ'iri, installé à Qom en Iran. Ce religieux, né en Iran, mais qui avait passé une grande partie de sa vie en Irak, où il figure parmi les fondateurs du parti Da'wa dans les années 1950, avait dû se résoudre à rejoindre l'Iran dans les années 1970, à cause d'activités politiques qui mettaient sa vie en péril. Partisans de la wilâyat $a l-f a q i h^{5}$, Kâzim al-Hâ'iri reconnaît aujourd'hui la marja'iyya de Khâmenâ'î, le Guide de la République islamique d'Iran, dont il est un proche conseiller. Muhammad Muhammad Sâdeq al-Sadr avait spécifié, "que mes imitateurs suivent l'ayatollah Kâzem al-Husayni al-Hâ'iri jusqu'à ce qu'un de mes élèves devienne marja'. " Désormais, Kâzim al-Hâ'iri sera considéré comme le successeur de l'ayatollah Muhammad Muhammad Sâdeq al-Sadr et la référence religieuse de son fils, Muqtada, qui n'a pas lui-même d'autorité religieuse propre. Bien que sa biographie présente Muqtada comme un mujtahid, la plupart des étudiants de la hawza de Nadjaf mettent en effet en doute qu'il ait même suivi un minimum d'études religieuses et rappellent qu'on ne l'a jamais vu fréquenter les séminaires des grands marja's. Sans avoir les qualifications religieuses requises, Muqtada s'est donc arrogé l'héritage de son père. A Sadr City, les portraits de l'ayatollah Muhammad Muhammad Sâdeq al-Sadr, que

\footnotetext{
${ }^{5}$ Théorie selon laquelle le pouvoir politique doit revenir au religieux le plus savant. Elle inspire le système politique iranien.
} 
l'on voyait seul ou en compagnie de Muqtada, ont sensiblement laissé la place à d'autres où Muqtada apparaît désormais seul.

Le 8 avril 2003, Kâzim al-Hâ'iri promulgua une fatwa pour appeler ses partisans à obéir à Muqtada et à ignorer l'occupation américaine, invitant les chiites à remplir le vide du pouvoir. Ce que les Sadristes faisaient précisément à Sadr City.

2) Les partis politiques chiites :

Aujourd'hui, l'immense majorité des chiites d'Irak se reconnaît dans des partis religieux chiites, illustration du retour en force du mouvement religieux au sein d'une communauté qui avait massivement adhéré à des idées politiques laïques (communistes et baassistes) au cours des années 1930-1960. La plupart de ces partis ont fait partie de l'opposition islamiste chiite au régime de Saddam Hussein réfugiée à Téhéran. L'Assemblée suprême de la révolution islamique en Irak (ASRII) a été fondée dans la foulée de la révolution islamique en Iran, en 1982, sous la présidence de Muhammad Bâqer al-Hakim. Interlocuteur privilégié des autorités iraniennes, ce fils d'un important marja' irakien mort en 1970 a formé en 1983 les Brigades Badr, bras armé de l'ASRII, en recrutant parmi les centaines de milliers de chiites irakiens réfugiés en Iran. C'est l'opposition chiite la plus structurée. Fidèle à la ligne de Khomeyni dans les années 1980 et 1990, attachée après la mort de Khomeyni à l'autorité du Guide de la République islamique d'Iran, l'ayatollah Khâmenâ'î, l'ASRII a entamé un virage radicale en 2003, avec la bénédiction de Téhéran. Après la chute de Saddam Hussein, ce virage lui a fait reconnaître l'autorité de Sistani en Irak et l'ASRII a rapidement accepté de participer au processus politique sous occupation américaine.

Après la mort de son chef en 2003, Abd al-Aziz al-Hakim, le frère de Muhammad Bâqer, a repris la tête du mouvement. Dépourvu de l'autorité de son prédécesseur, il a laissé la voie ouverte à des « laïcs ». Parmi ces derniers, Adel Abd al-Mahdi al-Muntafiki, vice-président chiite de l'Irak depuis 2005, est certainement le plus influent. Ancien membre du Baas qu'il a quitté en 1963, avant de flirter avec le maoisme, puis de rejoindre le mouvement religieux, un itinéraire classique pour de nombreux intellectuels arabes, Adel Abd al-Mahdi a vécu 23 années en exil en France. Il est considéré comme celui qui, au sein de la mouvance religieuse chiite, est le plus proche des Américains.

Principal partenaire de l'ASRII, le parti Da'wa occupait également une place importante au sein de l'ex-opposition au régime de Saddam. C'est le plus ancien parti islamiste chiite d'Irak et aussi le plus « irakien ». Fondé à la fin des années 1950, il a soutenu la révolution islamique en Iran avant que plusieurs de ses dirigeants ne restreignent la théorie de la wilayet al-faqîh d'une façon qui montrait leur désaccord avec le système politique iranien. Le parti Da'wa reconnait la marja'iyya de Sistani à Nadjaf, comme il reconnaissait celle de Khû'î avant lui. Ce parti a connu plusieurs scissions : il est divisé en 2006 en au 
moins cinq tendances qui s'opposent sur le degré d'allégeance envers l'Iran et son système politico-religieux. Parmi ses dirigeants, Ibrahim al-Ja'fari, docteur en pédiatrie, a passé la moitié de ses vingt années d'exil en Iran avant de gagner Londres. Il a été le premier chef de gouvernement élu en avril 2005 selon les termes de la Constitution. Premier ministre d'avril 2005 à mai 2006, il a dû reconnaître son échec à agir contre la violence et les milices et a passé le relais à Nuri al-Maliki. Second du parti Da'wa, ce dernier a passé un long exil en Syrie, puis en Iran. Constitutionnellement, il est premier ministre irakien jusqu'en 2010 .

\section{La mouvance sadriste au cour de la politique chiite}

La mouvance sadriste n'est pas un parti à proprement parler. Quand Muqtada al-Sadr, le seul fils de Muhammad Muhammad Sâdeq al-Sadr ayant survécu au massacre de 1999, apparaît pour la première fois sur la scène politique et religieuse, après l'occupation américaine, il incarne tout ce à quoi de nombreux chiites, notamment ceux de Sadr City, s'identifient : un patriotisme de l'intérieur, opposé aux directions de retour d'exil, une immense soif de reconnaissance et d'équité sociales, une méfiance envers les grands marja's, trop peu arabes pour certains et trop intellectuels, une vibrante affirmation identitaire et quasi-messianique cristallisée autour de l'ayatollah "martyr » Muhammad Muhammad Sâdeq al-Sadr, le père de Muqtada, qui devient une icône, l'exaltation de l'esprit chevaleresque, dans la plus pure tradition bédouine, au service de la bande ou de la milice. En 2003, Muqtada annonce la création de l'Armée du Mahdi, censée être l'armée islamique d'Irak. En plaçant son action sous l'autorité du Mahdi, le XIIe Imam occulté, Muqtada entend ainsi contourner la marja'iyya et pallier à son manque d'autorité religieuse propre. Brouillé avec son marja', Kâzim al-Hâ'iri, il trouve désormais dans le Mahdi la source de son autorité. En Iran, le millénarisme autour de l'attente messianique du Mahdi est utilisé par Ahmadinedjad pour les mêmes raisons. Malgré son indiscipline et ses pratiques relevant parfois du grand banditisme, l'Armée du Mahdi s'impose vite comme le grand rival des Brigades Badr de l'ASRII. En dehors de leur bastion de Sadr City, les Sadristes de Muqtada contrôlent un nombre croissant de quartiers de Baghdad, d'où ils ont chassé les sunnites, ainsi que les régions du Moyen-Tigre (Kout et Amara), dont sont originaires l'immense majorité des habitants de Sadr City.

Une branche de la mouvance sadriste, on l'a dit, était représentée par l'héritage revendiqué par l'ayatollah Muhammad al-Ya'qûbi à Nadjaf. Sur Muqtada, ce dernier a l'avantage d'une légitimité religieuse dont Muqtada ne peut se prévaloir. Malgré sa revendication, Muhammad al-Ya'qûbi a fait corps avec Muqtada jusqu'en 2004. Peu après la fin du siège de Nadjaf, en août 2004, où les miliciens de l'Armée du Mahdi ont affronté les troupes irakiennes secondées par les Américains, il a commencé à se désolidariser de Muqtada en apparaissant de façon distincte de lui sur la scène politique : le parti de la Vertu 
est créé. Présentant de fortes similitudes avec le Hezbollah libanais des débuts (un recrutement parmi des cadres éduqués, une autorité religieuse spécifique, à l'image de celle de Fadlallâh sur le parti libanais), ce parti prend désormais part à la vie politique de façon distincte de la mouvance de Muqtada. Il a développé son pouvoir et ses milices propres, notamment à Bassora, dont il contrôle plusieurs quartiers.

Enfin, il y a ce qu'on appelle les " chiites laïcs ». Le terme est utilisé abusivement aujourd'hui, car la laïcité en milieu chiite a été historiquement portée par les partis communiste et bassiste dans les années 1930-1960. Le parti communiste irakien, jadis le plus puisant du monde arabe, n'est plus que l'ombre de lui-même. Quant au Baas, son divorce avec les chiites, consommé en 1936, où il apparut comme un parti confessionnel sunnite, il y a longtemps qu'il ne représente plus les chiites. Ce qu'on entend par " chiites laïcs » est donc une appellation pour désigner les politiciens chiites qui se présentent en dehors d'un mouvement religieux hégémonique. Ses principales figures sont directement patronnées par l'une ou l'autre des administrations américaines : la CIA pour Ahmad Chalabi ou le Département d'Etat pour Iyad Allawi. L'Entente nationale irakienne de Iyad Allawi représente bien ces réseaux de clientélisme directement liés à l'occupation américaine : ancien baassiste recruté par les services de renseignements américains, Iyad Allawi devint, le 1 juin 2004, le premier chef de gouvernement irakien intérimaire après la chute du régime de Saddam, avant les élections législatives de 2005. Son passage à la tête du gouvernement fut marqué par la guerre qu'il mena, avec l'aide des Américains et la complicité tacite des autorités religieuses chiites, contre les partisans de Muqtada al-Sadr à Nadjaf en été 2004. Défait aux élections législatives, il laissa sa place le 7 avril 2005 à Ibrahim al-Ja'fari, du parti Da'wa, élu par la nouvelle Assemblée. Lors des élections législatives de fin 2005 , son parti subit à nouveau une sévère défaite. Ayant passé la moitié de sa vie en exil en Grande-Bretagne, dont il a la nationalité et ou vit sa famille, il réside aujourd'hui à Londres pour l'essentiel.

\section{3) Le régionalisme et les tribus :}

La société chiite d'Irak demeure marquée par sa forte identité tribale et régionale, une caractéristique que les chiites partagent avec les sunnites. Une important groupe tribal, les Chammar, dont une partie est sunnite et l'autre chiite, figure d'ailleurs en tant que tel parmi les forces réunies au sein de la Maison commune chiite, l'Alliance irakienne unifiée, une coalition créée à la fin de 2004 avec la bénédiction de l'ayatollah Sistani pour les besoins d'un vote communautaire chiite.

Le pays chiite peut être divisé en plusieurs entités, chacune dotée d'une forte identité. 
Il y a d'abord les quatre villes saintes chiites d'Irak: Nadjaf, Kerbéla, Kazimayn et Samarra. Siège traditionnel de l'autorité religieuse chiite, elles sont marquées par un certain cosmopolitisme puisque les oulémas et les étudiants y sont originaires d'Iran, du monde arabe, du sous-continent indien, d'Afghanistan ou d'Afrique. Cités des sciences religieuses et de l'enseignement de la religion, ces villes sont aussi le lieu d'un intense brassage intellectuel. Après l'attentat qui a visé le mausolée des Xe et XIe Imams chiites infaillibles à Samarra, le 22 février 2006, cette ville sainte, la seule à être située en pays sunnite, a perdu toute activité religieuse chiite, les partisans d'Al-Qaïda y menaçant de mort toute tentative d'un retour des chiites. Véritable siège de la marja'yiyya, Nadjaf, surtout, et Kerbéla ont tissé des liens forts avec les campagnes environnantes. On l'a vu lorsque, menacé par des Sadristes venus de Baghdad en 2003 et 2004, l'ayatollah Sistani a pu compter sur le soutien militaire des tribus du MoyenEuphrate contre les miliciens de l'Armée du Mahdi. Le mausolée de l'Imam Ali à Nadjaf et celui de Hussein à Kerbéla, les lieux les plus vénérés du chiisme, sont l'objet d'intenses rivalités entre l'ASRII et les Sadristes. L'ASRII a réussi à imposer son contrôle sur le mausolée de Nadjaf, avec le soutien de l'ayatollah Sistani, tandis qu'à Kerbéla, une situation conflictuelle oppose l'ASRII, les Sadristes et les partisans de l'ayatollah nouvellement "promu ", Mahmûd Sarkhi al-Hasani. A Kazimayn, la célèbre famille al-Khâlisi, héritière d'un combat prestigieux contre les Britanniques à l'époque du mandat, contrôle le sanctuaire des deux Kâzim, VIIe et IXe Imams chiites. Mais, opposés à la politique confessionnelle des dirigeants chiites, les al-Khâlisi vivent souvent comme assiégés dans leur propre quartier.

\section{Bassora, la grande ville du sud chiite}

Au sud, la grande ville de Bassora, chiite à $90 \%$, a le souvenir de l'époque où elle était la capitale du vilayet ottoman du même nom. A moitié détruite par la guerre entre l'Iran et l'Irak dans les années 1980, puis par les deux autres conflits qui ont suivi, la ville nourrit un fort sentiment d'être victime de la politique des autres. La proximité des champs de pétrole y a exacerbé les velléités d'autonomie. Le projet fédéraliste a trouvé dans la ville un écho chez certains notables et nouveaux chefs de guerre. Selon ce projet, Bassora pourrait se retrouver à la tête d'une super région du Sud pétrolier, avec les provinces du Bas-Euphrate de Muthanna (Samawa) et de Dhi Qar (Nasiriyya), les premières provinces chiites où le transfert de la sécurité aux forces irakiennes a été accompli (juillet et septembre 2006). La ville est l'objet d'intenses rivalités entre le parti de la Vertu, les Sadristes de Muqtada et l'ASRII, chacun tenant un ou plusieurs quartiers. D'autres acteurs locaux ont transformé leur quartier en base de pouvoir, rendant la situation dans la ville très instable. Les habitants des marais, chassés par la guerre entre l'Iran et l'Irak, avaient l'interdiction de pénétrer dans la ville à l'époque de Saddam Hussein. Entassés dans des camps de fortune à la périphérie de la ville, ils sont aujourd'hui utilisés comme des 
hommes de main par l'un ou l'autre camp en présence. En devenant un acteur urbain, le Hezbollah irakien, qui représente les chiites des marais, tente de faire oublier la mauvaise réputation de sa base, souvent créditée de tous les vices par les citadins. En ville, le parti de la Vertu a développé un réseau de bienfaisance important, ainsi qu'un centre d'études religieuses influent. Ses milices se sont heurtées à plusieurs reprises aux tribus des campagnes environnantes, dans une volonté affirmée d'asseoir son contrôle sur le trafic de pétrole.

\section{Amara et Kout, le Moyen-Tigre investit Baghdad}

Une autre région a joué un rôle essentiel dans l'histoire de l'Irak et, notamment, de Baghdad : le Moyen-Tigre. En Irak, les paysans sans terres des régions orientales du Tigre présentaient des grandes similitudes sociales et économiques avec les Metwalis du Sud Liban. Mais leur exode massif vers les grandes villes a précédé de plusieurs décennies celui des Metwalis. Les Sharâgwa qui vinrent s'entasser à l'emplacement de l'actuel quartier Sadr City à Baghdad à partir de la fin des années 1920 fuyaient un système mis en place par les Britanniques: les grands cheikhs tribaux étaient promus propriétaires terriens, une façon de briser la solidarité tribale qui était à la base des mouvements sociaux et politiques au sein de la communauté chiite. Des villages entiers des régions orientales du Tigre (provinces de Kout et Amara) furent vidés de leur population par un exode rural d'une ampleur sans équivalent dans le monde arabe.

Egalement appelés Shurûgiyyîn ou Shargâwiyya, les Shâragwa sont surtout des migrants en provenance des campagnes tribales de Amara. Avec environ trois millions d'âmes, ils constituent aujourd'hui de loin le groupe le plus important de la population de Baghdad, au point qu'il n'est pas exagéré de dire qu'il y a une " amarisation » de la capitale irakienne et, dans une mesure moindre, de Bassora.

Amara a joué un rôle important dans l'histoire moderne de l'Irak. L'afflux de Shâragwa à Baghdad augmenta en effet de façon spectaculaire la main d'œuvre non qualifiée. Si les Takrîtis et les Anites (originaires de Ana), tous sunnites, faisaient carrière dans l'armée, les Shâragwa furent recrutés en masse par la police, ou alors s'enrôlèrent sous la bannière communiste, et même souvent les deux en même temps. Les forces de police de Baghdad ont ainsi été très largement "amarizées ». Une tradition que les Sadristes ont reprise en infiltrant à leur tour la police. Il faut rappeler que ce sont les masses tribales citadinisées, et non pas les tribus, qui firent les principaux mouvements insurrectionnels qui secouèrent Baghdad sous la monarchie: Al-Wathba (Le Sursaut) de janvier-février 1948, l'Intifâda de novembre 1952, ainsi que la révolution antimonarchique de 1958. Les Shâragwa constituèrent la masse des manifestants qui, le 14 juillet 1958, envahirent les rues de Baghdad et renversèrent les statues, symboles de la monarchie et de la domination britannique. 


\section{Sadr City, les tribus chiites dans la ville}

Arrivés à Baghdad, les Shâragwa construisaient leurs sarîfas (cabanes en terre et en roseaux) sur les terrains vagues dans des zones où les crues du Tigre ne rencontraient aucun obstacle, en particulier au nord de la "digue-est ", construite pour protéger les quartiers centraux de Rusâfa (rive gauche du Tigre). Aucune mesure ne fut entreprise sous la monarchie pour améliorer le sort de leurs habitants. La grande majorité des Shâragwa, qui formaient une partie importante de la population des bidonvilles, demeurèrent dans leurs sarîfas de terre, en dehors de la ville.

La société tribale se recomposa dans le cadre nouveau de l'immense bidonville destiné à former Madînat al-Thawra (Révolution), nom donné par les communistes sous le régime de Kassem (1958-1963) à l'actuel quartier de Sadr City. Ce n'est qu'au début des années 1960 que de nouveaux barrages permirent à ce quartier misérable d'échapper aux crues dévastatrices et meurtrières du Tigre. Peu à peu, les $a k w a ̂ k h$, habitats de fortune de tôle et de roseaux, laissèrent la place à des maisons en dur, toujours aussi misérables, mais peu à peu intégrées à la ville et à ses services publics. Réputée comme un quartier socialement dangereux, Madînat al-Thawra fut quadrillée d'immenses artères donnant un libre accès à des chars, en cas de besoin. Dans les blocks (pâtés de maisons, au sens américain du terme) entre ces artères, les tribus anciennement rurales se regroupèrent par famille, tribu et village d'origine. Et en quelques années, la tribu recomposée devenait un clan urbain armé d'une nouvelle mythologie identitaire souvent sans rapport direct avec celle qui avait conduit au regroupement initial dans tel ou tel block. Madînat al-Thawra fournit le gros des milices liées au parti communiste dans les années 1950 et 1960. Entrer dans une milice du parti était une affaire de famille avant d'être celle du quartier. Fortement marquée par sa culture bédouine urbanisée, Madînat al-Thawra était, jusque dans les années 1980, presque totalement dépourvue d'institutions et d'autorités religieuses. Peu de mosquées et un nombre modeste de husayniyyas ${ }^{6}$, comparée à d'autres quartiers chiites. L'influence des villes saintes chiites y était peu visible. La religion était surtout un mode d'identification, autant social que religieux. Le leadership y était surtout " laïc », constitué par une multitude de chefs de quartier et de bande, se prévalant le plus souvent d'une origine tribale prestigieuse et/ou d'un statut de sayyid'. Le tout étant chapeauté par un fort sentiment d'appartenance à cet immense quartier (plus de la moitié de la population de Baghdad) que les autres Baghdadis ressentent encore comme hors-la-loi.

Pour ceux qui connaissent Baghdad et Beyrouth, Sadr City fait irrésistiblement penser à la banlieue sud de Beyrouth. Ex-bastion du parti communiste irakien, l'ancienne Madînat al-Thawra, que ses habitants n'ont

\footnotetext{
${ }^{6}$ Lieu où se célèbre les cérémonies de deuil de l'Achoura.

${ }^{7}$ Désigne chez les chiites plus particulièrement les descendants du Prophète par Hussein. Ils sont reconnaissables à leur turban noir.
} 
jamais voulu désigner sous son nouveau nom de Madînat Saddâm (la Ville de Saddam), a servi de déversoir à des populations rurales déshéritées, chassées de leurs terres autant par la misère et les rigueurs d'un système dominé par les grands propriétaires terriens que par les aléas politiques d'une répression antichiite qui a été croissante, si l'on excepte de courts intermèdes.

Sous le régime de Saddam Hussein, c'est avant tout une dynamique identitaire que manifeste ce quartier : chiite, à un moment où la répression à l'encontre des chiites prend des proportions terrifiantes, et sociale, pour un quartier laissé à l'abandon et réputé être un repère de voleurs.

Mais ce chiisme semble bien éloigné de celui des villes saintes, berceau du savoir et marquées par leur cosmopolitisme. L'ignorance en religion qui règne dans ce quartier misérable semble aux antipodes de la culture intellectuelle élitiste de la hawza. Peu à peu, le chiisme identitaire, qui se manifeste à travers les rites les plus ostentatoires, devient le ciment de tous les blocks du quartier. Ce qui n'empêche pas les rivalités de perdurer. Dans les années 1990, marquées par l'embargo, les baassistes avaient transformé leur patronage tribal en centres de pouvoir. Choisi par le régime de Saddam Hussein pour contrer Nadjaf et l'Iran, Muhammad Muhammad Sâdeq al-Sadr avait apporté une caution islamique à cette politique. Mais, à partir de 1997, il commença à revendiquer le droit de conduire en son nom la prière du vendredi, un pas que le gouvernement comprit comme une déclaration de guerre. L'assassinat du religieux avec plusieurs de ses enfants en 1999 suscita dans le quartier une flambée de violence sans précédent depuis l'intifâda chiite de février-mars 1991.

\section{Sadr City, première portion de territoire arabe d'Irak "libéré "}

Le 7 avril 2003, deux jours avant la chute officielle de Baghdad, les partisans de Muqtada al-Sadr se soulèvent, attaquent les postes de police, s'emparent des dépôts d'armes et prennent le pouvoir dans l'immense quartier déshérité de Madînat Saddâm. Ils le renomment Madînat al-Sadr (Sadr City). Avec près de trois millions d'habitants, la moitié de la population de Baghdad, le quartier passe sous le contrôle d'un mouvement alors pratiquement inconnu, que les Américains, notamment, avaient largement ignoré. Première portion du territoire irakien à accueillir le pouvoir de milices chiites locales, Sadr City est, depuis cette date, demeurée la seule enclave chiite où ce pouvoir ait été continu. La Jamâ'at al-Sadr al-Thânî ("Association du Second Sadr», du nom de l'ayatollah Muhammad Muhammad Sâdeq al-Sadr, le père de Muqtada) organise, dès les premiers jours de l'occupation, un nouveau pouvoir local, veille à l'ordre public, réglemente la vie des habitants, institue ses forces de police et sa justice au nom de la sharî'a.

\footnotetext{
${ }^{8}$ Le premier «Martyr Sadr» est l'ayatollah Muhammad Bâqer al-Sadr, cousin du second et promoteur du mouvement de renaissance islamique dans les villes saintes d'Irak à partir de la fin des années 1950 . Il fut assassiné par le régime de Saddam Hussein en 1980.
} 
La mobilisation de Sadr City, sous la direction des Sadristes, met ainsi en œuvre des ressources déjà rencontrées dans les quartiers d'autres grandes villes arabes, comme Michel Seurat a pu par exemple les décrire pour Bâb Tebbâne à Tripoli ${ }^{9}$. On peut même dire que Sadr City illustre au mieux comment des asabiyyas peuvent prendre le pouvoir ou s'instituer contre toute forme de domination extérieure au groupe, politique ou non. Le caractère exceptionnel de Sadr City tient au fait que ces 'asabiyyas de quartier peuvent, dans le cas actuel de l'Irak, être porteuses d'un véritable projet politique national.

Sadr City symbolise parfaitement l'attitude des Sadristes. Ces derniers ont développé une véritable stratégie politico-militaire pour faire de ce quartier une zone durablement libérée. Elle a d'abord consisté à expulser les forces américaines de leur domaine. Les partisans de Muqtada n'attaquent les forces de la Coalition hors de Sadr City que s'ils sont attaqués dans leur quartier. C'est une attitude défensive. Mais, si les Américains ou d'autres Irakiens entrent dans le quartier, l'Armée du Mahdi résiste avec acharnement. Il s'agit d'instaurer un rapport de force qui rend le quartier largement hors de portée des soldats américains, en dehors d'incursions meurtrières. Les Américains y viennent rarement et ils ne restent pas, ce qui permet au pouvoir parallèle qui s'est installé de perdurer. Si les Américains détruisent le bureau d'un représentant de Sadr, il est immédiatement reconstruit le lendemain.

Le quartier a été le théâtre de nombreux affrontements entre les forces de la Coalition et les habitants en 2003. Le 8 avril 2003, les Marines avaient occupé une usine de cigarettes, construite par Saddam dans le quartier et dirigée par un de ses cousins. Camp Marlboro devint une base militaire américaine temporaire pour le 2/2d Armored Cavalry Regiment. L'usine de cigarettes devait servir de QG pour « sécuriser » Sadr City avec 800 hommes assistés par 160 soldats de la police. En mai 2003, une unité de la police militaire de la $3^{\mathrm{e}}$ Division d'Infanterie arriva à Camp Marlboro pour mener des patrouilles dans BaghdadEst. Le 4 avril 2004, une embuscade de l'Armée du Mahdî à Sadr City faisait huit tués parmi les soldats américains : ce fut l'étincelle d'affrontements répétés entre l'Armée du Mahdi et les Américains jusqu'en juin 2004. En mars 2004, un autre régiment (1st Squadron, $2^{\text {nd }}$ Cavalry Regiment) s'installa à War Eagle Camp (situé en bordure du quartier) pour renforcer la sécurité de Sadr City. Le 25 juin 2004, l'Armée du Mahdi décréta un cessez-le-feu avec les forces de la Coalition et offrit de réparer les immeubles officiels et les services (le quartier est toujours largement privé d'eau, d'électricité et d'égouts). Le 10 octobre 2004, War Eagle Camp fut toutefois à nouveau attaqué ce qui provoqua le renforcement de sa défense. Le 11 octobre 2004, Weapons Handover Program commençait : il s'agissait d'un programme de ramassage des armes qui étaient rachetées. Mais l'opération ne sera jamais menée à bien et Sadr City resta hors de tout contrôle américain.

9 Seurat M (1985), «Le quartier de Bâb Tebbâné à Tripoli (Liban) : étude d'une 'asabiyya urbaine », in Mouvements communautaires et espaces urbains au Machrek, CERMOC, Beyrouth, pp. 45-86. La 'asabiyya désigne la solidarité tribale ou de groupe face à l'extérieur. 
Car, autant les forces américaines sont cantonnées dans des camps retranchés dont elles ne sortent que rarement, autant les nouvelles autorités irakiennes officielles ne sont à Sadr City que parce qu'elles sont tolérées et qu'elles servent la communauté. Avec ses forces de police, ses hôpitaux et sa distribution de nourriture, Sadr City jouit d'une réelle autonomie. Les habitants de ce quartier symbolique veulent y voir la préfiguration de l'indépendance de l'Irak.

Ailleurs dans la capitale, les miliciens de l'Armée du Mahdi se sont engagés dans une vaste campagne de « chiitisation » de Baghdad. Par la terreur et l'intimidation, ils ont chassé de nombreux sunnites de quartiers où ils représentaient parfois jusqu'à $40 \%$ des habitants (Ash-Sha'b, Talibiyya, Rahmâniyya, Karrâda, Baghdâd al-Jadîda sur la rive orientale, Shu'la, AlHurriyya, Kazimayn, sur la rive occidentale). A la fin de 2006, les sunnites ont pratiquement disparu de Ash-Sh'ab, Talibiyya, Shu'la, Al-Hurriya et Kazimayn, sans parler de Sadr City.

\section{Les communautés chiites hors le "pays chiite »}

Enfin, il y a les communautés chiites éparpillées hors du " pays chiite»: quartiers de Baghdad hors Sadr City, Dujayl, Ba'qûba, Tell Afar, Kirkouk, Samarra. Elles se retrouvent aujourd'hui confrontées au déchaînement de l'antichiisme, cible privilégiée des Takfîris (les " excommunicateurs »), nom donné par les chiites aux fondamentalistes sunnites. On estimait, à la fin de 2006, à environ 300000 le nombre de déplacés dont une bonne part de ces chiites vivant dans des quartiers mixtes de Baghdad ou dans ces régions où se mélangeaient jusque là sunnites, chiites, Arabes, Kurdes, Turkmènes. Dans le quartier mixte à majorité sunnite de Dawra, au sud-ouest de Baghdad, d'immenses barrières de béton ont séparé les deux communautés en 2006, apportant un répit aux habitants épuisés par des vagues d'attaques meurtrières. La province de Diyala, à l'est de Baghdad, continue à concentrer une bonne partie des actes de terrorisme anti-chiite avec la capitale. A Kirkouk, les Turkmènes, chiites dans leur majorité, ont trouvé un soutien important en Muqtada al-Sadr contre les revendications des Kurdes sur la ville. Même chose à Samarra, où le mouvement sadriste a manifesté son intention de reconstruire la mosquée détruite en février 2006, sans succès jusqu'à ce jour puisque la région est devenue " interdite » aux chiites. La ville chiite de Hilla, au nord du « pays chiite », jouxte une zone d'une trentaine de kilomètres qui la sépare de Baghdad, où les sunnites sont majoritaires et où règne la plus grande violence. Sous le régime de Saddam Hussein, de nombreuses terres de Hilla avaient été données aux sunnites. Au lendemain de la chute du régime irakien, les chiites de Hilla se sont engagés dans une politique de provocations à l'égard de leurs voisins sunnites plus au nord. La réponse a été terrible avec des campagnes d'attentats régulières contre Hilla, tandis que cette zone, lieu de passage obligé pour gagner 
Baghdad depuis le sud et les villes saintes chiites, est devenue le lieu de tous les dangers pour ceux qui la traversent, notamment les oulémas chiites.

\section{$\underline{B}$ - Les chiites dans le processus politique :}

\section{Le « droit de la majorité »}

Pendant la guerre de 2003, l'ayatollah Sistani avait considéré que seuls les services de sécurité étaient habilités à porter les armes. On était donc loin d'un appel à la lutte armée alors même que des soldats "infidèles » envahissaient l'Irak. Une majorité de chiites en était en effet arrivée à la conclusion que seule une intervention extérieure pouvait les libérer du régime en place. C'est cette ambiguité qu'exprima Sistani. En juin 2003, Sistani prit une position remarquée: les élections au suffrage universel, déclara-t-il, sont nécessaires pour légitimer tout nouveau gouvernement, la Constitution devant être rédigée par des Irakiens élus, et il exigeait dans la foulée que soit respectée l'identité islamique du pays. En se faisant le chantre du suffrage universel, Sistani n'apparaissait-il pas comme un leader patriotique irakien, voire le Mandela d'Irak comme certains n'hésitèrent pas à le présenter ? L'attachement de Sistani à la tenue d'élections au suffrage universel relève d'abord de la revendication du " droit de la majorité » (dont on sait qu'elle est arabe et chiite) et, à ce titre, apparaît bien plus comme l'expression d'une vision confessionnaliste. Sistani n'est pas partisan d'une seconde république islamique en Irak. Mais son choix dépend largement de partis chiites (parti Da'wa, ASRII,), proches de Téhéran ou nés dans la foulée de la révolution islamique en Iran. Ce rapprochement avec les partis chiites se fait avec la bénédiction de Téhéran qui semble se ranger derrière l'autorité du marja' Sistani, désormais considéré par tous comme l'autorité religieuse suprême. Ainsi, majorité démographique et majorité démocratique sont confondues. Sortant de son quiétisme traditionnel, Sistani utilise son autorité religieuse immense auprès des chiites pour adouber le système politique qui se met en place. Il réussit à contraindre les autorités de la Coalition à un compromis sur le processus constitutionnel. La place de l'islam est réaffirmée, et la Constitution finale est débattue par des Irakiens élus en 2005. L'ayatollah Sistani appelle le 22 septembre 2005 à voter «oui» au référendum constitutionnel, appel repris par l'ayatollah Ishâq al-Fayyâd.

Sans réaliser probablement que son «droit de la majorité » condamne chiites et sunnites à s'opposer, il émet plusieurs fatwas appelant les chiites à s'abstenir de toute représailles face au terrorisme anti-chiite qui fait des dizaines de milliers de morts. Après l'attentat qui a détruit la mosquée de Samarra, en février 2006, les chiites ont commencé à répondre sur une grande échelle au terrorisme qui les frappe depuis plus de deux années : des esquadrons de la mort, infiltrés dans la police ou dépendant du ministère (chiite) de l'Intérieur, ont 
lancé à leur tour des campagnes anti-sunnites meurtrières, sans plus se soucier visiblement des avis de leur chef religieux. Une guerre impitoyable prend alors une ampleur terrifiante, sans ligne de front, faite d'enlèvements massifs suivis d'exécutions, d'assassinats, d'attentats de plus en plus meurtriers.

\section{Muqtada et la marja'iyya}

Face à l'establishment chiite constitué par la marja'iyya et la classe politique chiite, l'émergence de Muqtada al-Sadr a commencé peu après la marche forcée des troupes américaines à travers l'Irak. Après leur prise du pouvoir dans le plus grand quartier de Baghdad, les Sadristes vont rapidement se manifester de façon violente à l'encontre de l'establishment religieux chiite. Le 3 avril 2003, alors que les troupes américaines, britanniques et polonaises s'enfonçaient dans le sud irakien sur la route de Baghdad, Abd al-Majid Khû'î, le fils aîné de l'ayatollah défunt, revenu en Irak dans leur sillage, fut assassiné à Nadjaf où il était venu rencontrer Sistani. Trois jours plus tard, cent membres de la Jamâ'at al-Sadr al-Thânî encerclaient la maison de Sistani à Nadjaf, lui intimant l'ordre de «retourner en Iran dans les quarante-huit heures». Le siège prit fin seulement après que Sistani eut fait appel à 1500 hommes des tribus des campagnes environnantes. Les hommes des tribus parvinrent à disperser la foule menaçante. Les représentants de la hawza firent une enquête et déclarèrent Muqtada responsable du meurtre de Khû̀'î. Ils rendirent les résultats de leur enquête à un officier des Marines qui le transmit à ses supérieurs, mais l'autorité de la Coalition ne prit aucune mesure dans l'immédiat.

La confrontation entre Muqtada et la marja'iyya avait commencé dans le sang. Les Sadristes reprochait à Abd al-Majid d'être un exilé revenu dans le train américain, alors qu'eux se revendiquent d'un "chiisme de l'intérieur et patriotique ». Ils l'accusaient aussi de vouloir entraîner l'ayatollah Sistani à collaborer avec la Coalition. A l'ayatollah Sistani enfin, ils reprochaient d'être "Iranien" et de ne pas s'opposer ouvertement à l'occupation de l'Irak. Le 11 avril 2003, Muqtada fit son premier sermon à la mosquée de Koufa, qui allait devenir sa tribune.

Les frictions avec la population des villes saintes ne cessèrent pas. Plusieurs Nadjafis furent arrêtés par la milice des partisans de Muqtada et déférés ensuite devant des tribunaux religieux institués en son nom, où certains furent condamnés à mort. En même temps, les biens privés étaient volés au nom de la religion. Ces excès conduisirent les habitants de Kerbéla à déclarer Muqtada « pire que Saddam ». Il y avait aussi des conséquences économiques au défi de Muqtada. Les troubles empêchaient la hawza de collecter d'immenses sommes d'argent en provenance des pèlerins et de riches donateurs. Le 15 octobre 2003, les miliciens de Muqtada tentèrent de s'emparer des mausolées de l'Imam Husayn et de Abbâs à Kerbéla : les heurts avec les partisans de Sistani firent des dizaines de morts. A Nadjaf, les Sadristes rééditèrent leur tentative de prise de contrôle du mausolée de l'Imam Ali, causant des heurts sanglants avec 
les milices Badr de l'ASRII. Cette dernière s'était, il est vrai, adjugée le contrôle du mausolée et du sermon qui y était prononcé le vendredi, avec l'assentiment de la marja'iyya.

\section{Que veut Muqtada?}

Le départ immédiat des troupes américaines, et s'il y a des troupes étrangères en Irak, qu'elles soient sous commandement onusien - il refuse par la même occasion des troupes envoyées par la Ligue arabe, qu'il accuse d'avoir soutenu le régime de Saddam Hussein ; le rétablissement d'un gouvernement central irakien fort, mais qui aurait coupé tout lien avec les baassistes ; un Irak uni, ce qui l'a amené à refuser le fédéralisme, soutenu par l'ASRII et dans une bien moindre mesure par le parti Da'wa, à dénoncer les revendications des Kurdes et à soutenir les Turkmènes chiites de Kirkouk face aux velléités kurdes d'annexer la ville ; que le chiisme irakien s'affirme face à l'Iran; même s'il parle parfois de démocratie pour l'Irak d'après l'occupation, cela signifie probablement un régime où ses milices imposent par la force un ordre moral puritain. Sur le long terme, il n'a jamais mis en avant une réelle vision d'un gouvernement islamique (sauf pour rejeter le modèle iranien). Les Sadristes dénoncent le consumérisme occidental et la globalisation américaine, mais c'est dans l'activisme de la rue qu'ils se définissent le mieux. Et cet activisme est très largement marqué par le caractère local de l'implantation des Sadristes. A Sadr City et dans les villes du sud qu'ils contrôlent, les Sadristes ont nommé des religieux aux mosquées, gardé les hôpitaux, organisé la collecte des ordures, recueilli les orphelins et donné accès aux Irakiens les plus pauvres au minium vital.

Muqtada se manifeste surtout par son refus de l'occupation. Il est le premier en Irak à exprimer un tel refus et le seul dirigeant chiite à déclarer l'occupation illégitime. Dès ses premiers sermons, il martèle: "Nous ne reconnaissons pas l'occupation, ni directement ni indirectement, puisqu'elle est contraire au souhait du peuple irakien et que sa direction politique et religieuse la rejette totalement. » En fait, les grands marja's n'ont pas appelé à combattre l'avancée des forces de la Coalition et ils ont même invité les Irakiens «à ne pas prendre parti » entre les Américains et l'armée irakienne loyale à Saddam, renvoyés dos à dos pour l'occasion. Toutefois, Muqtada invite à une résistance pacifique et condamne la violence aveugle.

\section{Muqtada et le choix communautariste des Américains}

Pendant les discussions pour former le Conseil de gouvernement intérimaire (CGI), en mai 2003, le pro-consul américain Paul Bremer approche le parti Da'wa et l'ASRII, mais ignore Muqtada. Les Américains ont en effet une connaissance des partis bien structurés de l'ex-opposition en exil au régime de Saddam Hussein, dont ils ont patronné les conférences à plusieurs reprises, mais ne savent pas ce que la mouvance informelle de Muqtada leur réserve. Ce 
dernier aurait-il alors intégré le processus politique s'il avait été convié au même titre que les autres forces chiites? Toujours est-il que, se trouvant exclu, il remit aussitôt en question la légitimité du CGI et qu'il s'engagea dans une complète opposition aux institutions créées par l'Autorité provisoire de la Coalition. Dans un sermon incendiaire devant des milliers des chiites à Koufa, le 18 juillet 2003, Muqtada a condamné le Conseil de gouvernement de 25 membres nommés par les Etats-Unis, les qualifiant $\mathrm{d}^{\text {' }}$ incroyants ». Interviewé sur Al-Jazira, il déclare que le CGI est « un jouet des Américains » et condamne les ministres, affirmant qu'ils ont été « choisis sur une base communautaire et non en regard de leurs compétences ». Avant d'ajouter : "Ce gouvernement est le résultat d'une décision illégitime du Conseil de gouvernement intérimaire qui est luimême illégitime car il a été nommé par une force d'occupation illégitime. " Muqtada annonce alors qu'il va former son propre gouvernement et fonder une armée religieuse, l'Armée du Mahdi, tandis qu'il appelle à « une mobilisation générale pour combattre les occupants américains et britanniques ». Il ajoute que cette armée utilisera des moyens pacifiques et condamne les attaques-suicides contre les soldats de la Coalition. Le 10 octobre 2003, Muqtada nomme un gouvernement parallèle, un défi direct au CGI. Parlant depuis Koufa, il déclare : «J'ai formé un gouvernement comprenant des ministères de la justice, des finances, de l'information, de l'intérieur et des affaires étrangères ». Jusqu'alors, les Américains avaient largement ignoré Muqtada, tout en lui permettant d'instaurer son pouvoir et sa conception de l'ordre islamique à Sadr City.

\section{Le soulèvement sadriste de 2004}

La constitution provisoire, écrite par des experts américains et rendue publique en février 2004, suscite une levée de boucliers générale chez les chiites. L'ayatollah Sistani sort de sa réserve relative pour affirmer qu'elle est " inacceptable ", car elle engage l'Irak sur une voie où le peuple n'aura pas été consulté. Le leitmotiv de la marja'iyya est en effet devenu les élections libres au suffrage universel, qui devraient consacrer le « droit de la majorité (c'est-à-dire des chiites). Muqtada n'est pas en reste quand il s'agit de dénoncer la " constitution de l'occupant». A longueur de sermons, il vitupère contre un texte qu'il juge comme «une déclaration de guerre au peuple irakien». L'Autorité provisoire de la Coalition n'avait à ce moment sévi qu'une fois contre un journal (Al-Mustaqilla, interdit pour son soutien présumé à la résistance sunnite irakienne). Ce sera alors le tour de l'hebdomadaire de Muqtada, Al-Hawza al-nâtiqa (La Hawza qui parle, en opposition à la hawza dite « silencieuse » de Sistani et des grands marja's), interdit le 28 mars 2004. Et le 3 avril, le représentant de Muqtada, Mustafa al-Ya'qûbi, est arrêté par les Américains, officiellement pour le meurtre de Abd al-Majid Khû'î. Le 4 avril, un ordre d'arrestation contre Muqtada est lancé pour les mêmes motifs. Les manifestations pacifiques sont alors la cible de tirs américains et de la police irakienne. On dénombre plusieurs morts. Peu après, Muqtada déclare que 
désormais les «protestations pacifiques sont devenues sans utilité » et il appelle ses partisans « à terroriser leurs ennemis. » Dans un sermon, il invoque l'histoire lointaine et récente : "La mémoire de la Révolution de 1920 et de l'intifâda sha'bâniyya (le soulèvement chiite de 1991) est encore fraîche. " Il sera entendu dans ses bastions, à Sadr City, Kout, Nasiriyya. Quelques troubles éclateront également à Bassora. Mais, ailleurs, rien ne se passera. Le local prédomine.

La Coalition ne parvint toutefois pas à réduire le soulèvement rapidement et Muqtada gagnait en popularité et en audace. Une audace qui se manifestera, une fois de plus, contre la hawza et Sistani. Les Sadristes bloqueront même les rues conduisant aux demeures de Sistani et d'Ishâq alFayyâd, un des cinq marja's présents à Nadjaf, et les deux villes saintes de Nadjaf et de Kerbéla tomberont alors sous leur contrôle. Les Sadristes prennent alors les mausolées comme refuges, pensant que la Coalition ne les poursuivra pas dans ces enceintes sacrées. Des tribunaux sont formés pour juger les opposants, notamment les membres de l'ASRII.

\section{Le siège de Nadjaf}

Face à ce qui ressemble à un coup de force, les plus hautes autorités de la hawza condamnent l'annonce faite par Muqtada d'une fatwa appelant ses partisans à se sacrifier si les forces de la Coalition entraient dans Nadjaf et Kerbéla pour poursuivre les miliciens de l'Armée du Mahdi qui y sont retranchés. Dans un communiqué, les marja's dénient à Muqtada les qualifications requises pour émettre une telle fatwa et rejettent aussi toute idée de permission pour mener des attaques-suicides contre les forces de la Coalition.

Le 11 avril 2004, l'Autorité provisoire de la Coalition lui soumet une proposition pour résoudre le conflit à trois conditions : qu'il disperse sa milice, respecte les institutions gouvernementales et retire ses hommes armés des lieux publics. C'est Nuri al-Maliki, du parti Da'wa, qui fait l'intermédiaire. Muqtada répond par ses propres conditions : que les forces de la Coalition se retirent de Nadjaf, Kerbéla et Koufa. Les médiations se succédaient et Muqtada répondait à chaque fois qu'elles émanaient d'un gouvernement illégitime. Selon le journal Az-Zaman, "Muqtada n'accepterait aucun accord tant qu'il serait exclu du processus politique ». Quelles qu'aient été à ce moment les arrièrepensées du chef des Sadristes, Paul Bremer fit monter la pression en affirmant qu'il fallait "capturer» Muqtada ou bien le tuer. Mais il ne sera ni tué ni capturé. L'Autorité provisoire de la Coalition promulgua alors un décret où elle interdisait à Muqtada toute activité politique pour trois ans. Cette menace apparut vaine, puisque, après le transfert de souveraineté de juin 2004, dénoncé par Muqtada comme une "farce », le gouvernement irakien d'Iyâd Allawi pressa Muqtada de rejoindre le processus politique de reconstruction du pays.

Fidèle à son refus de toute forme de gouvernement « non élu par le peuple », Muqtada dénoncera le gouvernement transitoire d'Iyâd Allawi et jurera qu'il n'aurait rien à voir avec lui « jusqu'au jour du Jugement dernier. » 
Dans ses sermons prononcés lors des prêches en juin, Muqtada affirmait qu'il « soutiendrait le gouvernement, s'il manifestait plus de souci pour l'opinion publique irakienne que pour les intérêts des occupants. » De son côté, Ghazi alYâwer, le président irakien sunnite, était dénoncé pour avoir serré les mains de Bush.

Après des semaines de médiations, les troupes américaines attaquèrent les positions de Muqtada à Nadjaf, Kerbéla et Koufa, tuant des centaines de ses partisans, et confisquant leurs armes et munitions, la plupart cachées dans des mosquées. Dans un terrain qui leur était désormais hostile, les milices de Muqtada, indisciplinées et sans expérience, pouvaient difficilement résister face à l'assaut conjoint des forces de la Coalition et de la Garde nationale irakienne. En désespoir de cause, Muqtada appela à l'aide la hawza pour qu'elle dénonce l'incursion américaine dans les villes saintes. Ses appels ne reçurent pas de réponse. La hawza était trop heureuse de voir Muqtada vaincu ou, au moins, expulsé des villes saintes. Le flot des pèlerins s'était interrompu et les marchands d'articles religieux, qui font vivre l'économie des villes saintes, étaient désormais les plus farouches opposants aux miliciens de Muqtada.

Le 27 mai 2004, Muqtada et les forces de la Coalition avaient conclu un cessez-le-feu qui impliquait le retrait de ses milices de Nadjaf. Au début, Muqtada sembla s'y conformer. Il appela les combattants de l'Armée du Mahdi « qui se sont dépensés corps et âme pour plaire à Dieu et à leur peuple » à retourner dans leurs provinces. Mais il devint vite évident que le message de Muqtada n'était qu'un écran de fumée. Son contrôle des mausolées demeura effectif. A la mi-août, Muqtada contrôlait encore le mausolée de l'Imam Ali, menaçant de détruire les pipe-lines et d'incendier les puits de pétrole s'il était attaqué dans l'enceinte sacrée, alors que les combats ensanglantaient Wâdî alSalâm, la grande nécropole de Nadjaf.

Le gouvernement irakien d'Iyad Allawi décida alors d'engager l'épreuve de force : il lança un ultimatum demandant à Muqtada de rendre les armes, d'évacuer la ville sainte et d'accepter publiquement les termes du cessezle-feu, sinon il s'exposerait à la force militaire. A sa façon désormais typique, Muqtada rejeta d'abord l'ultimatum, puis promit de l'accepter et de rendre aux préposés de la hawza les clés du mausolée. Quand il parut qu'il était à nouveau revenu sur son engagement, la police irakienne, la Garde nationale et les forces américaines passèrent à l'attaque. On était le 19 août 2004. Des centaines de civils furent tués. Les forces de Muqtada, retranchées dans l'enceinte du mausolée, subirent d'immenses pertes, mais l'action militaire échoua à les expulser du mausolée ou à contraindre Muqtada à remettre les clefs du mausolée, jusqu'à ce que l'ayatollah Sistani obtienne un cessez-le-feu qui prit effet le 27 août. L'Armée du Mahdi avait le droit de se retirer avec ses armes, en vertu d'un accord secret avec le gouvernement d'Iyad Allawi. 
Sistani était à Londres depuis un mois pour soigner un problème cardiaque. Le retour de l'ayatollah en Irak, le 25 août 2004, fut accueilli avec soulagement par tous les chiites, dont bon nombre se mirent en route pour Nadjaf (la date coïncidait avec l'anniversaire de la naissance de l'Imam Ali, une des rares occasions où les chiites se réjouissent). Comme une haie d'honneur, une immense marche pacifique pour « la défense des Lieux saints », qui, par son ampleur, prit des allures à la fois épiques et historiques, accompagna le marja' depuis Bassora jusqu'à la ville sainte, là où une invitation similaire de Muqtada, deux semaines auparavant, pour défendre les Lieux saints face aux Américains avait été largement ignorée. L'arrivée triomphale de l'ayatollah à Nadjaf semblait consacrer la victoire de la marja'iyya et la défaite des Sadristes. Cependant, la résistance "héroïque » des miliciens de l'Armée du Mahdi face aux forces combinées américano-irakiennes valut à Muqtada un prestige qui dépassait la communauté chiite. Désormais, Muqtada était le chiite le plus populaire parmi les sunnites. "Il ne peut y avoir de politique sous occupation, pas de liberté sous occupation, pas de démocratie sous occupation » répétera-t-il après avoir évacué Nadjaf. Dans un sondage de juin 2004, demandé par l'Autorité provisoire de la Coalition, $81 \%$ des Irakiens avaient répondu que leur opinion de Muqtada était «meilleure» ou «bien meilleure » qu'avant l'insurrection.. 92\% considéraient les forces américaines comme des forces d'occupation, $2 \%$ comme des libérateurs et $55 \%$ voulaient les voir partir immédiatement. Seules les villes saintes, occupées à panser les terribles ravages des combats, semblaient persister dans leur hostilité envers les Sadristes.

\section{C-Les chiites pris au piège du confessionnalisme :}

Les gagnants des élections législatives du 30 janvier 2005, puis du 15 décembre 2005, les chiites et les Kurdes, parviendront-ils à transformer leur victoire électorale en conquête du pouvoir? Quel lieu de pouvoir y a-t-il à investir en Irak ? Ces élections ont été la consécration d'un processus entamé à l'initiative des Américains, le 13 juillet 2003, lorsqu'ils nommèrent le premier gouvernement provisoire. Seul le critère de l'appartenance communautaire était retenu. Déjà, on retrouvait ces quotas infernaux : $60 \%$ de chiites, $20 \%$ de Kurdes et $20 \%$ d'Arabes sunnites. Comment un tel système, dont les Libanais cherchent à se débarrasser et qu'ils rendent responsable des quinze années de guerre civile qu'a connues leur pays, pourrait-il avoir des vertus insoupçonnées sur les rives du Tigre et de l'Euphrate?

Il est vrai que les chefs de la Coalition n'avaient guère d'autre choix. Le fait qu'il existe en Irak une autorité suprême qui n'est pas irakienne condamne chaque acteur politique et religieux à négocier avec celle-ci au nom d'intérêts 
communautaires contradictoires plutôt que de s'engager dans la recherche d'un consensus national dans le cadre d'un projet patriotique. En 2005, comme en 1920 , le corollaire de l'occupation étrangère est le communautarisme. Les Britanniques avaient misé sur les élites issues de la minorité arabe sunnite excluant dès le départ les chiites, puis, à partir de 1925, les Kurdes. En 2005, on prend les victimes d'hier et on recommence, si l'on peut dire. Les Américains s'adressent ainsi aux exclus du système fondé par les Britanniques.

Le vice d'un tel procédé, c'est que, la puissance occupante ne pouvant satisfaire des revendications contradictoires, il fabrique à son tour des exclus. Aujourd'hui, ce sont les Arabes sunnites qui se retrouvent à l'écart. Les Américains ont cru pouvoir reconstruire l'Irak sous leur égide en opposant les Irakiens les uns aux autres. Mais le piège dans lequel sont tombés les dirigeants chiites se retourne aussi contre les Américains. Comment pourraient-ils se désengager s'il ne se trouve aucun gouvernement stable et légitime à qui remettre le pouvoir? Les GI's ne pourront alors ni rester en Irak ni en partir.

En 2004 et 2005, les élections ont été précédées d'une guerre meurtrière. La stratégie de reprise des villes rebelles, faites d'un mélange d'ultimatum, de négociations et d'offensives militaires, s'est soldée par des dizaines de milliers de morts. Falloudja, Nadjaf, Kout, Ramadi, Samarra, Mossoul, Ba'qouba, Tell Afar ont été reconquises une à une.

Sans surprise, la liste de l'Alliance irakienne unifiée (AIU), qui a la bénédiction de l'ayatollah Sistani, s'arroge la part du lion avec 51\% des voix en janvier 2005. Mais la liste de l'AIU est loin d'être monolithique. Sur les 140 sièges remportés, une partie non négligeable l'ont été par des partisans de Muqtada al-Sadr. Ils constituent le premier mouvement non seulement de la liste chiite, mais d'Irak, surtout si l'on y ajoute les sièges du parti de la Vertu.

\section{Muqtada et les élections}

Muqtada a-t-il alors rallié un processus politique qu'il condamnait jusqu'alors ? La montée des tensions communautaires entre chiites et sunnites a affecté en premier lieu les Sadristes qui entendaient maintenir un front islamique uni entre chiites et sunnites contre l'occupation. Cette volonté se manifestait par des liens étroits avec le Comité des Ulémas sunnites et la solidarité publiquement affichée par Muqtada envers les «martyrs de Falloudja ». Mais le déchaînement du terrorisme anti-chiite a touché en premier les plus déshérités, qui constituent la base sociale des Sadristes. En réponse, Muqtada a adopté une stratégie politique qui pourrait se résumer par « un pied dehors un pied dedans ». Tout en dénonçant le processus politique en cours, il a laissé ses partisans se présenter aux élections, où ils raflent souvent la mise.

Le 1er septembre 2005, Muqtada annonce qu'il va consulter Sistani (une première !) à propos de la violence confessionnelle. Quelques jours auparavant, des partisans de Muqtada lui avaient, depuis Koufa, adressé une lettre pour lui demander son avis « au nom des partisans de la ligne sadriste, en 
particulier, et des chiites, en général » concernant la déclaration de Zarqâwî jetant l'anathème contre les chiites. Cette déclaration - diffusée ensuite le 14 septembre 2005 par un message vocal sur un site djihadiste - avait été faite « en représailles aux massacres à Tell Afar » et elle s'est accompagnée d'attentats meurtriers contre les chiites, dont beaucoup de partisans de Muqtada. Muqtada, qui est alors le chiite le plus populaire parmi les Arabes sunnites - et qui est souvent accusé par certains chiites, notamment l'ASRII, de collaborer avec « les ennemis des chiites »- ne voulait pas prendre la responsabilité de déclarer que les chiites devaient s'abstenir de représailles face aux attaques anti-chiites. La réponse de Muqtada vint en trois points : 1) «Reportez-vous pour cette question à vos nobles marja's, qui sont, comme il est connu, Sayyid Sistani (Que Dieu lui accorde longue vie) et Sayyid al-Hâ'iri (Que Dieu lui accorde longue vie). Ils doivent être consultés en premier et, s'ils n'interviennent pas, revenez me voir pour une nouvelle réponse. 2) Publiez des livres et des manuels d'éducation à la fois contre l'occupation et ses conséquences, les brigands wahhabites et takfîr (c'est-à-dire les " excommunicateurs ", le nom que les chiites donnent aux partisans de Zarqâwî) et les baassistes. 3) Appelez les imams à la prière du vendredi à jeter l'anathème sur eux, Que Dieu les maudisse, ces apostats ! " En conclusion, Muqtada appelait à préserver l'unité de l'islam et l'unité des chiites " qui est leur meilleur arme » contre « les brigands et leurs maîtres et contre les baassistes. " Quelques jours après son appel à faire la guerre aux chiites, Zarqâwî avait fait une exception pour les Sadristes, qui se verraient épargnés pour avoir lutté contre l'occupation. Mais la réponse de Muqtada fut immédiate : «C'est une manœuvre misérable pour diviser les chiites. S'il tombe entre nos mains, nous le mettrons en pièces. "

Sistani répondit par un communiqué officiel publié en arabe sur son site : "Ceux qui veulent diviser les Irakiens et les pousser vers la guerre civile ont pour objectif d'empêcher l'Irak de recouvrir sa souveraineté et sa sécurité. Les Irakiens ne doivent pas tomber dans ce piège quelles que soient les horreurs qui leur sont infligées. Les chiites doivent s'abstenir de réagir et coopérer avec les services officiels pour leur protection dans la région où ils vivent. Tous les Irakiens doivent appeler à repousser, en mots en en sermons, les dépravés déviationnistes. Le gouvernement irakien doit assurer la sécurité à tous les Irakiens, quelle que soient leur religion et leur appartenance ethnique.»

\section{La guerre confessionnelle se déchaîne : le ralliement de Muqtada}

Le mois d'octobre 2005 vit les affrontements confessionnels prendre de l'ampleur. Dans le district de Nahrawân, à l'est de Baghdad, on voit, pour la première fois, les Brigades Badr venir au secours de l'Armée du Mahdi contre la guérilla sunnite. La dynamique confessionnelle prend le dessus: Muqtada a laissé ses partisans voter en faveur de la Constitution le 15 octobre 2005 et, le 28 octobre, face à la guerre larvée entre sunnites et chiites qui fait de plus en plus de victimes, il annonce finalement qu'il participera aux élections 
générales prévues pour le 15 décembre 2005 et qu'il rejoint la coalition chiite unifiée. Les partisans de Muqtada intègrent donc la liste de l'Alliance irakienne unifiée : comme préalable, ils ont insisté pour avoir la parité avec l'ASRII et pour qu' «il n'y ait pas de reconnaissance de l'entité sioniste », une "ligne rouge qui ne saurait être dépassée sous quelque prétexte que ce soit. " Sous le nom de Bloc sadriste, les Sadristes pensent conquérir plus de trente sièges et avoir une position dominante à Baghdad, Amara, Kout, Hilla, Diwaniyya, Samawa. Dans certains endroits, ils seront en coalition avec le parti Da'wa-Irak (Abd al-Karîm al-Anzi) ou le parti Da'wa islamique (du premier ministre Ibrahim al-Ja'fari).

Les Sadristes vont aux élections du 15 décembre 2005 sous trois couleurs : à côté du Kutlat al-Sadr, le Bloc de Sadr, qui rassemble les partisans de Muqtada, il y a le parti de la Vertu des partisans de Muhammad al-Ya'qûbi, qui domine Bassora et est influent dans le Moyen-Euphrate, et enfin la liste des Risâliyyûn (Les Porteurs du Message), une liste de Sadristes opposés à l'Alliance irakienne unifiée et notamment, en son sein, à l'ASRII. Elle est dirigée par un collaborateur de Muqtada, Cheikh Abd al-Hâdî al-Darrâji, dont la base est Sadr City. Il semble que cette liste indépendante visait à capter le vote de ceux qui, parmi les Sadristes, étaient réticents à voter sur la même liste que l'ASRII. D'autres Sadristes sont présents sur des listes indépendantes.

Les élections confirment l'éclatement communautaire de l'Irak: les chiites ont voté pour des chiites, les Kurdes pour des Kurdes, les Arabes sunnites pour des Arabes sunnites, les Turkmènes pour des Turkmènes, les Yézidis pour des Yézidis, les chrétiens pour des chrétiens, et ainsi de suite. Le scrutin donne une majorité relative à l'Alliance irakienne unifiée (128 sièges sur 275). Cette moindre majorité par rapport aux élections législatives précédentes s'explique par la participation massive, cette fois-ci, des Arabes sunnites. Une fois encore, la mobilisation de la communauté chiite a été forte. Au sein de l'Alliance irakienne unifiée, le Bloc sadriste se retrouve la première force avec 29 sièges, auxquels il faut ajouter les 15 sièges du parti de la Vertu, soit en tout 44 sièges. Quant à la liste des Risâliyyûn, elle n'obtient à Baghdad que 1,8\% des votes contre 58,5\% pour l'AIU. A Bassora, un autre bastion des Sadristes, cette liste hors l'AIU n'a recueilli que $0,5 \%$ des voix contre $77,5 \%$ à l'AIU. A Nadjaf, elle culmine avec $4 \%$ des voix contre $82 \%$ à l'AIU. Ceci montre que l'immense majorité des Sadristes a voté pour la Maison commune chiite incarnée par l'AIU, conséquence de la polarisation communautaire, après que les partisans de Muqtada eurent été les principales victimes des attentats anti-chiites. Comme Sistani l'a recommandé, il n'y a pas eu de dispersion des voix chiites sur des petites listes. Au niveau national, les Risâliyyûn gagnent deux sièges, ce qui porte à 46 le nombre de sièges obtenu par les Sadristes, bien plus que l'ASRII ou que chacune des deux branches du parti Da'wa engagées dans les élections. Par ailleurs, de nombreux Sadristes figurent sur la liste des « indépendants ». Pour un mouvement qui, il y a un peu plus d'un an, était assiégé dans le 
mausolée de l'Imam Ali à Nadjaf et qui suscitait la condamnation unanime de la hawza, c'est une revanche fracassante.

\section{Les Sadristes au gouvernement et au Parlement}

Les Sadristes acceptent désormais de participer au gouvernement, mais refusent des postes importants qui les mettraient en contact avec les Américains. Ils réclament en revanche des postes " au service des Irakiens ", comme le ministère de l'Electricité ou de la Santé. Quatre candidats étaient en lice au sein de l'AIU pour le poste de premier ministre: le chef du gouvernement sortant, Ibrahim al-Ja'fari, du parti Da'wa, Adel Abd al-Mahdi, vice-président sortant et représentant de l'ASRII, Nadim al-Jabiri, secrétaire général du parti de la Vertu, et Husayn Shahrestani pour les indépendants. Les deux branches du mouvement sadriste se sont divisées sur la question du premier ministre. Le parti de la Vertu, dirigé par Muhammad al-Ya'qûbi, a choisi Adel Abd el-Mahdi, tandis que le Bloc sadriste de Muqtada lui a préféré Ibrahim al-Ja'afari. A Téhéran, ceux qu'on qualifie de "conservateurs" semblent avoir donné leur préférence à Adel Abd al-Mahdi (cf. les éditoriaux du journal Baztab). Ce dernier se présente aujourd'hui comme un partisan du libre marché, ce qui en a fait aussi le candidat préféré des Américains. Nadîm alJâbiri et Husayn Shahrestâni ayant retiré leur candidature avant le vote, c'est finalement entre Adel Abd al-Mahdi et Ibrahim al-Ja'fari que tout s'est joué. C'est le premier ministre sortant Ibrahim al-Ja'fari qui a été élu nouveau premier ministre au terme d'un scrutin secret interne à la liste de l'AIU, auquel les deux députés des Risâliyyûn ont été autorisés à participer. Un score serré puisqu'alJa'fari a obtenu 64 voix et Adel Abd al-Mahdi 63 voix.

Le caractère hétérogène de l'AIU a vite montré les limites du vote communautariste chiite. Le parti de la Vertu l'a quitté et a menacé de lui retirer son soutien si le premier ministre ne faisait rien contre la spirale de la haine communautaire et s'il ne réussissait pas à améliorer la sécurité. Muqtada s'est positionné pour l'après-élection dans les tractations pour la formation d'un nouveau gouvernement sur la base suivante : pas d'alliance avec les baassistes ni avec Iyâd Allawi, ce qui réduisait singulièrement les possibilités de trouver une majorité stable sur autre chose que des accords ponctuels.

Les oppositions n'ont pas disparu malgré ce vote communautaire. Le 31 décembre 2005, Muqtada avait appelé à une alliance entre Arabes sunnites et chiites contre les Kurdes. Il faut rappeler que la plupart des Turkmènes de Kirkouk sont chiites et qu'ils sont partisans de Muqtada qui leur a déjà manifesté sa solidarité, face à l'ASRII, soupçonnée de vouloir "vendre " les chiites de Kirkouk aux Kurdes contre une zone « purement chiite » au sud.

\section{Muqtada capitalise sa victoire électorale}

Par ailleurs, Muqtada peaufine son image régionale. Pour la seconde fois, il se rend en visite en Iran en janvier 2006, d'où il appelle à la 
solidarité avec la République islamique en cas d'agression américaine. Une nouvelle fois, sa proximité avec Ahmadinedjad est mise en valeur. Dans la foulée, il entame une tournée régionale pour apaiser les craintes des pays arabes sunnites face à l'arrivée au pouvoir des chiites en Irak. Après un pèlerinage à La Mecque, sa tournée l'amène de Syrie, en Jordanie, puis au Liban. A Damas, où il arrive le 5 février, il jure fidélité à la Syrie face à Israël, à la Grande-Bretagne et aux Etats-Unis. Dans une interview donnée depuis Amman à Al-Jazira le 18 février 2006, Muqtada annonce: "Nous sommes prêts à attaquer les Américains, s'ils agressent l'Iran ou la Syrie ». Depuis la capitale syrienne, tout en appelant les sunnites à débarrasser l'Irak d'Al-Qaïda et de Zarqâwî, Muqtada invite à l'unité des sunnites et des chiites dans l'affaire des caricatures danoises du Prophète. Il déclare à Reuters le 10 février 2006 à ce propos : "C'est une croisade occidentale et une campagne contre l'islam.» Il se compare alors volontiers à Hassan Nasrallâh du Hezbollah libanais, se déclare proche du Hamas de Palestine: "Nos idées sont similaires, puisque nous sommes confrontés à une même oppression et à l'occupation, ainsi qu'à la corruption que tout l'Occident veut répandre dans la région et dans les pays musulmans. " L'attentat contre le mausolée chiite de Samarra le contraint à rentrer précipitamment en Irak.

Parallèlement, les Sadristes continuent à défendre leurs bastions, en s'opposant par les armes aux Américains, comme c'est le cas lors d'une incursion de ces derniers à Sadr City en janvier 2006. Ils continuent aussi d'être à la pointe de l'ordre moral islamique et de la lutte contre les blasphèmes. Ainsi, ils sont plus de 5000 à manifester à Kout contre le Danemark. Le journal $\mathrm{Al}$ Hawza demande au Pape de condamner les caricatures, tandis que les Sadristes se posent en protecteurs des chrétiens d'Irak après les attaques dont ont été victimes les églises de Baghdad. A Bassora, le conseil de province dominé par les Sadristes rompt avec le commandement britannique, exigeant le départ du contingent danois, mais aussi pour dénoncer les mauvais traitements infligés à de jeunes irakiens révélés par des images vidéos. Il est imité quelques jours plus tard par le conseil provincial de Misân (Amara), également sous le contrôle des Sadristes.

\section{Le gouvernement mis en échec}

Le gouvernement de Ibrahim al-Ja'fari est vite confronté à un cercle vicieux. Depuis plus de deux ans, le rapport de forces en Irak a basculé en faveur de forces locales. Les Kurdes avaient été les premiers, avec les Sadristes de Sadr City, à inaugurer un processus qui s'est ensuite généralisé : sur le terrain, le pouvoir n'est plus assumé directement par les forces de la Coalition, mais par des milices de partis, souvent liées au tribalisme local, avec la complicité des forces de sécurité irakienne, notamment le police, infiltrée par les milices chiites rivales. Les partis du gouvernement dépendent eux-mêmes d'un rapport de force qui joue en faveur des forces locales. En l'absence d'Etat 
capable de protéger ses citoyens, chacun se replie sur le plus petit dénominateur commun : le clan, la tribu, le quartier. Les chiites ne peuvent que compter sur leurs milices pour les protéger des Takfiris. Les sunnites, pour leur part, accusent le premier ministre de protéger les esquadrons de la mort chiites alors que le cycle des attentats et des représailles s'intensifie. Les jours du gouvernement Ja'fari, resté incomplet durant de longs mois, sont comptés.

Après d'âpres négociations, Ja'fari cède sa place à Nuri al-Maliki, désigné par l'AIU. Un nouveau gouvernement est enfin formé le 20 mai 2006. Les chiites de l'AIU y ont 17 portefeuilles. Outre le poste de premier ministre, ils contrôlent le ministère de l'Intérieur (les Sadristes ont la Santé et les Transports). Les Kurdes ont les Affaires étrangères, la présidence de la République et la tête de l'armée. Les Arabes sunnites ont la Défense et la présidence du parlement.

Avec la participation aux dernières élections de 2005 des politiciens sunnites, peu représentatifs et qui n'empêchent pas l'insurrection de redoubler, celle de Muqtada, le dernier outsider d'un processus politique qui semble voué à l'échec, semble hypothéquer un peu plus l'avenir. Dernier espoir d'une unité nationale aux yeux de nombreux sunnites, Muqtada a été rattrapé par la violence confessionnelle. Son ralliement à un processus qu'il dénonçait a correspondu à une rapide perte de contrôle sur ses troupes. De plus en plus, l'Armée du Mahdi semble obéir à des chefs locaux qui ne reconnaissent plus d'autre autorité que locale. A l'automne 2006, des miliciens sadristes se sont affrontés à l'armée irakienne à Diwaniyya dans le Moyen-Euphrate, faisant de nombreuses victimes. Les appels à cesser le feu de Muqtada n'ont pas été entendus. Ses miliciens se lancent désormais à corps perdu dans le cycle infernal des représailles contre les sunnites. Le 9 juillet 2006, des miliciens de l'Armée du Mahdi ont assassiné des passants sunnites au vu de leurs papiers d'identité dans le quartier Al-Jihad de Baghdad. L'Armée du Mahdi dépasse désormais en horreur dans ses exactions contre les sunnites celles auparavant attribuées aux seules Brigades Badr. La perspective de transfert de la sécurité exacerbe les tensions. A Amara, la police, infiltrée par les Brigades Badr, s'est opposée en octobre 2006, lors de combats meurtriers, aux milices de la ville, contrôlée par les Sadristes. Les conflits semblent de plus en plus perdre tout contenu politique : les clivages communautaires sont dépassés par des stratégies de prise du pouvoir local. On peut dire que la guerre est largement devenue « incivile », dans le sens où elle oppose de façon croissante des intérêts particuliers au sein d'une société en cours d'implosion généralisée. Le 30 novembre 2006, les 32 députés du groupe de Sadr ont suspendu leur participation au gouvernement en protestation contre la rencontre Bush-Maliki à Amman. Le gouvernement Maliki est désormais minoritaire, mais peu importe... entre une impossible réconciliation et une impossible partition, l'Irak continue sa descente aux enfers sans que rien ni personne ne paraisse en mesure d'y mettre un coup d'arrêt.

Décembre 2006 
